\title{
Infrared Spectroscopy of Anionic, Cationic, and Zwitterionic Surfactants
}

\author{
Rommel B. Viana, ${ }^{1}$ Albérico B. F. da Silva, ${ }^{1}$ and André S. Pimentel ${ }^{2}$ \\ ${ }^{1}$ Departamento de Química e Física Molecular, Instituto de Química de São Carlos, Universidade de São Paulo, São Carlos, SP, Brazil \\ ${ }^{2}$ Departamento de Química, Pontifícia Universidade Católica do Rio de Janeiro, Rio de Janeiro, RJ, Brazil
}

Correspondence should be addressed to Rommel B. Viana , rommelbv@yahoo.com.br and André S. Pimentel, a_pimentel@puc-rio.br

Received 21 January 2012; Revised 7 April 2012; Accepted 8 April 2012

Academic Editor: Michael D. Sevilla

Copyright ( $) 2012$ Rommel B. Viana et al. This is an open access article distributed under the Creative Commons Attribution License, which permits unrestricted use, distribution, and reproduction in any medium, provided the original work is properly cited.

This paper describes the ordering degree of anionic, cationic, and zwitterionic surfactants with the increase of their packing density on Ge substrate by using Fourier transform infrared-attenuated total reflection (FTIR-ATR) spectroscopy. This work shows new insights on the conformational order of sodium dodecyl sulfate (SDS), N-hexadecyl-N-N-dimethyl-3-ammonio-1-propanesulfonate (HPS), hexadecyl-trimethylammonium bromide (CTAB), and dodecyl trimethylammonium bromide (DTAB). DFT and semiempirical calculations are also performed in order to evaluate the effect of headgroup hydration and $\mathrm{counterion}^{\mathrm{T}} \mathrm{The}_{\mathrm{CH}}$ asymmetric and symmetric stretching bands for the SDS molecule show a shift of 1.7 and $0.9 \mathrm{~cm}^{-1}$ to higher frequencies as the packing density increases, while it is observed a shift of 2.6 and $2.7 \mathrm{~cm}^{-1}$ for the HPS molecule, respectively. The DTAB molecule shows a shift of $4.5 \mathrm{~cm}^{-1}$ to lower frequencies for both $\mathrm{CH}_{2}$ asymmetric and symmetric stretching bands as the packing density increases, indicating the decrease of gauche conformations and the increase of all-trans conformations over the aliphatic chain.

\section{Introduction}

Surfactants have been widely studied due to its significance in both applied and fundamental processes: detergency, catalysis, flotation, lubrication, colloid stabilization, foaming, emulsification, protein denaturation, tension moderation in membranes, membrane permeation, and drug delivery [1]. Surfactants are also used to the syntheses of nano- and mesomaterials using their capability to form self-organized aggregate structures [2]. Therefore, the determination of the packing, ordering, and its relation to the properties of the surfactant aggregates is of fundamental importance $[3,4]$.

Sperline [5] and Sperline et al. [6] have studied several crystalline phases of sodium dodecyl sulfate (SDS) using transmission infrared techniques. They have pointed out some relevant aspects: (1) difficulty in assigning a degree of order to the packing of alkyl chains based on the asymmetric $\mathrm{CH}_{2}$ stretching band; (2) the molar absorptivities for the alkyl vibrational features of adsorbed structures may not be compared with those for SDS micellar solutions;
(3) the relative abundances of the $\mathrm{CH}_{2}$ symmetric and asymmetric stretching bands of SDS change considerably with the crystalline phase. In other words, the nature of the packing of surfactant molecules may determine their molar absorptivities.

Snyder et al. [7], Flach et al. [8], and Dicko et al. [9] show that the frequency of the $\mathrm{CH}_{2}$ asymmetric stretching feature decreases with the conformational ordering in the hydrocarbon chain of polymers and phospholipids. However, the quantitative correlation between the magnitude of the shifts and the ordering extent has remained obscure and elusive. Since then, the asymmetric $\mathrm{CH}_{2}$ stretching band has been used as a reference for ordering in any kind of surfactant containing a methylene hydrocarbon chain. In fact, Prosser and Franses [10] and Scheuing and Weers [11] indicate that this feature correlates with the packing density and the conformational order of hydrocarbon chain tail of surfactants.

The cross-section of the sulfate headgroup is about $3.0 \times$ $10^{-17} \mathrm{~cm}^{2}$ molecule ${ }^{-1}$ as reported by Vold and Vold [12] 
and Sigal et al. [13]. However, the cross-section of a tightly packed SDS monolayer is about 100 times larger, $3.3 \times$ $10^{-15} \mathrm{~cm}^{2}$ molecule ${ }^{-1}[14,15]$. Besides, a condensed SDS monolayer film electrochemically reorganized shows a value of $2.1 \times 10^{-15} \mathrm{~cm}^{2}$ molecule ${ }^{-1}$ [16], while the theoretically value is predicted to be $2.4 \times 10^{-15} \mathrm{~cm}^{2}$ molecule ${ }^{-1}[17,18]$. Therefore, the amount of surfactant material deposited over a solid substrate is dependent on the deposition procedure, packing and ordering of the surfactant.

The purpose of the present study is to prepare crystallites of surfactant on Ge substrates and assign the infrared features of these crystallites by using Fourier transform infraredattenuated total reflection (FTIR-ATR). This study describes the vibrational features of an anionic SDS, cationic surfactants (hexadecyl-trimethylammonium bromide (CTAB) and dodecyl trimethylammonium bromide (DTAB)), and a zwitterionic surfactant (N-hexadecyl-N-N-dimethyl-3-ammonio-1-propane-sulfonate (HPS). In this study, the surfactants are directly prepared over an ATR Ge element to evaluate the packing density and organization of the alkyl chain conformation for each surfactant.

\section{Materials and Methods}

SDS (purity > 99\%), CTAB (purity > 99\%), DTAB (purity > 99\%), and HPS (purity > 99\%) were obtained from SigmaAldrich Co. Methanol (HPLC grade) was purchased from J. T. Baker and used as received.

The casting technique was applied to estimate the surfactant density over the ATR Ge element. The casting technique consisted in spreading an aliquot over one of the ATR Ge element faces by using a Teflon bar. It was assumed that the surfactant covers $90 \%$ of the ATR element. All surfactant solutions were made with deionized water (Millipore, MilliQ, resistivity $18 \mathrm{M} \Omega \mathrm{cm}$ ), and prepared with $40 \%$ (V/V) of methanol. It is important to mention that the solutions were prepared below the c.m.c for all surfactants employed in this study. The volume added over the Ge substrate was varied from 2 to $10 \mu \mathrm{L}$. Then, the Ge substrate with the surfactant was put in a desiccator coupled with vacuum pump operating at a pressure of $\sim 1 \times 10^{-2}$ Torr. This procedure eliminates the remaining solvent excess from surfactant in about 10 minutes. The whole deposition equipment was kept in a clean environment at room temperature to avoid complications with the presence of dust particles. It is important to assign that the depositions were performed layer-by-layer in order to vary the density from $10^{14}$ to $10^{18}$ molecules $\mathrm{cm}^{-2}$.

The infrared spectra of the transferred surfactant were collected on a Varian/Digilab FTS7000 spectrometer equipped with a high sensitivity narrow band liquidnitrogen-cooled mercury-cadmium-tellurium (MCT) detector. The sampling was performed using Horizon ATR accessory (Harrick Scientific Inc.). The ATR theory and accessory are fully described in the literature [19]. It consists of a set of two plane mirrors to direct the infrared beam into the ATR Ge element and then to the MCT detector. The ATR Ge element is a single-pass trapezoid with dimension of $2 \times 10 \times 50 \mathrm{~mm}$ and a bevel angle $(\theta)$ of $45^{\circ}$. The length
( $l$ ) and thickness $(t)$ of the ATR Ge element determine the number of reflections $(N)$ by the formula $N=l t^{-1} \tan \theta$, which gives 25 internal reflections. For each spectrum, 128 single-beam scans were averaged with $1 \mathrm{~cm}^{-1}$ resolution for the reference and sample. Prior to deposition, the ATR Ge substrate was cleaned with a suitable procedure [19] until the $\mathrm{CH}_{2}$ signal was eliminated. The reference spectrum was obtained by transmitting the infrared beam along the ATR Ge substrate alone, after which the sample spectrum was taken immediately after transferring the surfactant onto the ATR Ge element.

Theoretical Calculations. The calculations were carried out with the Gaussian software [20] and MOPAC package [21]. Stationary points on the potential energy surface were fully optimized, followed by the evaluation of the harmonic vibration frequencies in order to characterize their nature as minima. The absence of imaginary frequencies indicated that all optimized structures were true minima. Quantum chemical calculations were performed with Becke's three parameter hybrid functionals (B3LYP), which include a mixture of HF exchange with DFT exchange correlation. B3LYP functional [22] uses the nonlocal correlation provided by the LYP expression [23]. The 6-311++G(d,p) basis set was employed. AM1 [24], RM1 [25], and PM6 [26] were employed for semiempirical calculations.

\section{Results and Discussions}

3.1. Deposition Techniques. The addition of methanol as a cosolvent in the standard surfactant solutions is an important aspect that must be commented. It was tried to evaluate the preparation of the surfactant solution with the absence of methanol. The problem is that some surfactants show a broad band in the spectral region between 1300 and $900 \mathrm{~cm}^{-1}$, which may be due to the water crystallization. The addition of several percentages of methanol as a cosolvent $(20,40$, and $60 \%)$ was tried to solve this matter, nevertheless $40 \%$ seemed to avoid perfectly this problem to each surfactant. Prosser and Franses [10] had pointed out that the contamination by residual ethanol may cause two problems in the preparation of the cast films. First, they observed a shift of $6 \mathrm{~cm}^{-1}$ of the $\mathrm{CH}_{2}$ antisymmetric stretch for higher frequencies, which was also followed by a non clear region between 1500 and $800 \mathrm{~cm}^{-1}$ indicating a lack of crystalline structure in the cast film with ethanol. An explanation to this problem is that ethanol may penetrate the micelle [27]. After eliminating the solvent, some ethanol may intercalate between the surfactant molecules, disordering the crystalline structure. In our case, methanol is completely eliminated as it can be seen due to the absence of the infrared features in 3328,1418 , and $1030 \mathrm{~cm}^{-1}$, which refers to $\nu(\mathrm{O}-$ $\mathrm{H}), \delta(\mathrm{O}-\mathrm{H})$, and $\nu(\mathrm{C}-\mathrm{O})$ for methanol, respectively.

de Souza et al. [28] observed that drying procedures affect the morphology of the crystalline structure. The samples dried under room conditions seem to be more homogeneous than those dried under vacuum or by nitrogen flow [28]. Silva et al. [29] show that the hydrocarbon chains are more ordered using spontaneous water evaporation 
than those dried by nitrogen flow. They suggested that the spontaneous water evaporation reduces the effect of dragging by the drying front. However, the fast water evaporation in the process of nitrogen-flow drying "freezes" the disordered conformation chains. In addition, Halthur et al. [30] commented that drying procedures do not result in any irreversible changes in the conformational structure. In this study, in order to evaluate the influence of drying procedure, some tests were performed to observe the effects of spontaneous solvent evaporation at room temperature and by the use of vacuum pump. It is important to mention that none difference was observed in the vibrational spectra of the surfactants for small amount of materials. Nevertheless, a broad band in the region between 1300 and $900 \mathrm{~cm}^{-1}$ is observed for depositions with large amount of materials, larger than $10^{16}$ molecules $\mathrm{cm}^{-2}$. This is observed only for anionic and zwitterionic surfactants. However, it was preferred to use the vacuum pump drying for eliminating the solvent for all surfactants, keeping this procedure as standard.

\subsection{Anionic Surfactant}

3.2.1. $\mathrm{C}-\mathrm{H}$ Stretching Region. The vibrational frequencies in the $\mathrm{C}-\mathrm{H}$ stretching region for the SDS molecule can be observed in Figure 1(a). The asymmetric $v_{\text {as }}\left(\mathrm{CH}_{3}\right)$ and symmetric $v_{s}\left(\mathrm{CH}_{3}\right) \mathrm{CH}_{3}$ stretching vibrational frequencies are located at 2955 and $2873 \mathrm{~cm}^{-1}$, respectively. The asymmetric and symmetric $\mathrm{CH}_{2}$ stretching vibrational frequencies $\left(v_{\text {as }}\right.$ $\left(\mathrm{CH}_{2}\right)$ and $\left.v_{\text {sym }}\left(\mathrm{CH}_{2}\right)\right)$ are observed at 2917 and $2849 \mathrm{~cm}^{-1}$, respectively. The $\mathrm{CH}_{3}$ stretching intensities are lower than those for the $\mathrm{CH}_{2}$ stretching features as expected. The $\mathrm{CH}_{2}$ asymmetric and symmetric stretching features can be used to ascribe the packing and conformation of SDS molecules on Ge substrate due to the fact that the $\mathrm{C}-\mathrm{H}$ stretching of alkyl chain assemblies is sensitive to the conformation of methylene chains. For example, when the $v_{\text {sym }}\left(\mathrm{CH}_{2}\right)$ band presents values lower than $2852 \mathrm{~cm}^{-1}$, it is a good indicative of a more ordered crystalline structure, while values higher than that are representative of micelles and liquid crystals [5]. Besides, a shoulder at about $2860 \mathrm{~cm}^{-1}$ indicates the coexistence of noncrystallized SDS and hydrated crystalline SDS [31]. This shoulder is not observed in our study.

The $\mathrm{CH}_{2}$ asymmetric stretching appears at $2917 \mathrm{~cm}^{-1}$, suggesting a high ordering hydrocarbon chain in all-trans $\mathrm{CH}_{2}$ configuration [7-9]. The band shift from higher $2917 \mathrm{~cm}^{-1}$ to lower frequencies means that the number of gauche conformers decreases and the number of highly ordered all-trans conformers of alkyl chain increases. This reflects a change from more disordered (liquid phase) to a more crystalline (solid phase) conformation. The $v_{\mathrm{as}}\left(\mathrm{CH}_{2}\right)$ band of SDS micelles are observed between $2936-2928 \mathrm{~cm}^{-1}$ [31] and it is clearly dependent on its concentration. In addition, Sperline et al. [6] show that the asymmetric stretching $v_{\mathrm{as}}\left(\mathrm{CH}_{2}\right)$ for the SDS molecules in the liquid crystal phase is around $2924 \mathrm{~cm}^{-1}$. The $v_{\text {as }}\left(\mathrm{CH}_{2}\right)$ feature in our study is different from those described above, however, it is similar to those determined in the literature $[5,10]$.
Nevertheless, it is important to mention that each study used different preparation methods.

Figure 2(a) presents the relationship between packing density and the asymmetric stretching $v_{\mathrm{as}}\left(\mathrm{CH}_{2}\right)$ feature. As the packing density increases on Ge substrate, it is observed that the band shifts to higher frequency values. The shift is only $1 \mathrm{~cm}^{-1}$ as the packing density of SDS molecules changes by a factor of 1000 . The $\mathrm{CH}_{2}$ symmetric feature has the same behavior observed in the $\mathrm{CH}_{2}$ asymmetric band as presented in Figure 2(b). The $v_{\text {sym }}\left(\mathrm{CH}_{2}\right)$ shift is similar to that observed to the $v_{\text {as }}\left(\mathrm{CH}_{2}\right)$ band. However, due to this small shift in $v_{\text {as }}\left(\mathrm{CH}_{2}\right)$ and $v_{\text {sym }}\left(\mathrm{CH}_{2}\right)$ modes, it just indicates the high ordered all-trans conformers.

3.2.2. $\mathrm{CH}_{2}$ Scissoring Region. Additional information about the alkyl chain conformation is also obtained with the location of $\mathrm{CH}_{2}$ scissoring mode, $\delta\left(\mathrm{CH}_{2}\right)$. This feature is very sensitive to side-by-side chain interactions as well as the packing organization of the methylene chain [32-35]. Low $\delta\left(\mathrm{CH}_{2}\right)$ intensities and frequencies around $1466 \mathrm{~cm}^{-1}$, and band broadening indicate a reduction of side-by-side chain interactions and an increase in chain motion, which is normally associated with the liquid state [32, 33, 35]. Besides, a frequency higher than $1472 \mathrm{~cm}^{-1}$ is an indicative of an alltrans conformation. Nevertheless, the $\delta\left(\mathrm{CH}_{2}\right)$ band in this study is located at $1468 \mathrm{~cm}^{-1}$ as presented in Figure 1(b), which is a characteristic of partially ordered chains $[33,34]$. The shoulder at $1457 \mathrm{~cm}^{-1}$ is also an indicative of partially ordering conformation, which is generally associated with a combination of gauche defects and the asymmetric deformation of the terminal $\mathrm{CH}_{3}$ group $[32,33]$.

3.2.3. $\mathrm{CH}_{2}$ Wagging Region. The spectral region located in $1300-1400 \mathrm{~cm}^{-1}$ is a characteristic of the $\mathrm{CH}_{2}$ wagging modes. This region exhibits peaks which are related to gauche conformations [36, 37]. The peak at $1341 \mathrm{~cm}^{-1}$ indicates an end-gauche $(e-g)$ conformation with a terminal $\mathrm{CH}_{3}$ group oriented in a gauche conformation relative to the $\mathrm{CH}_{2}$ group. In addition, the peak at $1354 \mathrm{~cm}^{-1}$ is an indication of two adjacent gauche bonds $(d-g)$, and the peak at $1368 \mathrm{~cm}^{-1}$ is due to a gauche-trans-gauche sequence $(g-t-g)$. Nevertheless, a very weak peak at $1341 \mathrm{~cm}^{-1}$ is observed in our study, suggesting an $e-g$ conformation. This low intensity is also characteristic of the crystalline phase in the case of micelle structures [35-38]. Furthermore, it is also observed a very weak band at $1378 \mathrm{~cm}^{-1}$ which refers to the $\mathrm{CH}_{3}$ umbrella mode.

3.2.4. Headgroup Vibrational Region. The $\mathrm{SO}_{2}$ asymmetric vibrational feature $\left(\nu_{\text {as }}\left(\mathrm{SO}_{2}\right)\right)$ is the most intense band in the SDS spectrum. It is a combination of several overlapping peaks, and it is generally observed as double band [10]. As observed in Figure $1(\mathrm{c}), v_{\mathrm{as}}\left(\mathrm{SO}_{2}\right)$ is located at 1219 and $1249 \mathrm{~cm}^{-1}$. The separation between these two peaks is an indicative of the conformational structure. The band separation of $30 \mathrm{~cm}^{-1}$ presented in our study is similar to that observed by Prosser and Franses [10], nevertheless higher than that found by Sperline [5] for the SDS crystalline 


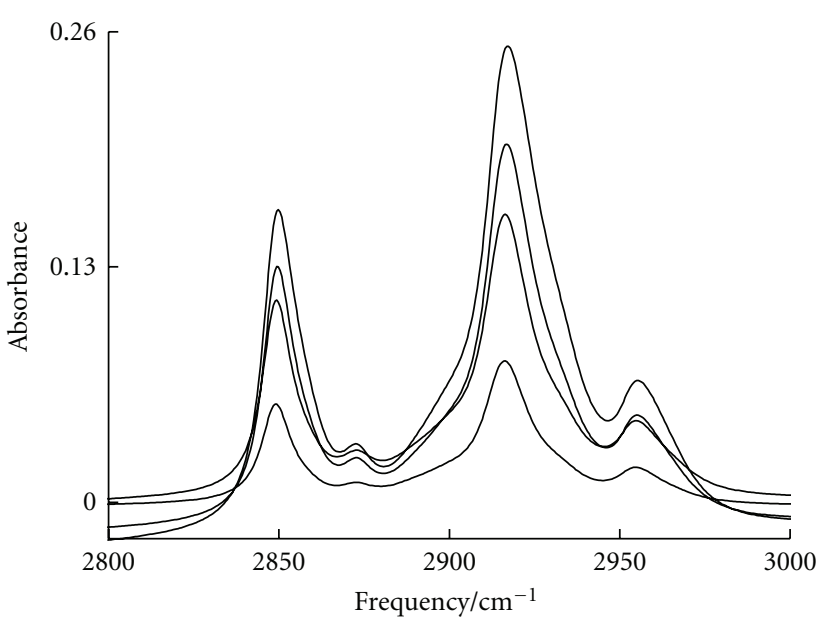

(a)

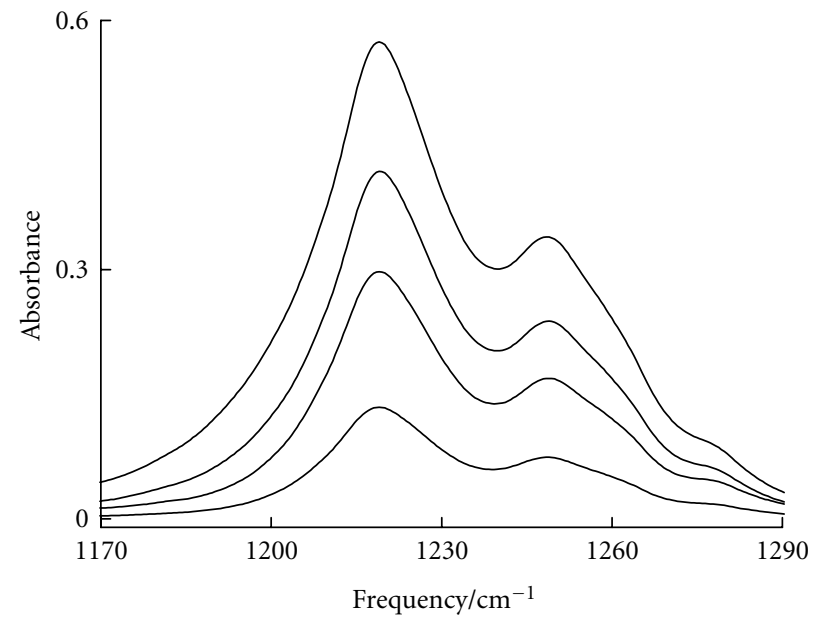

(c)

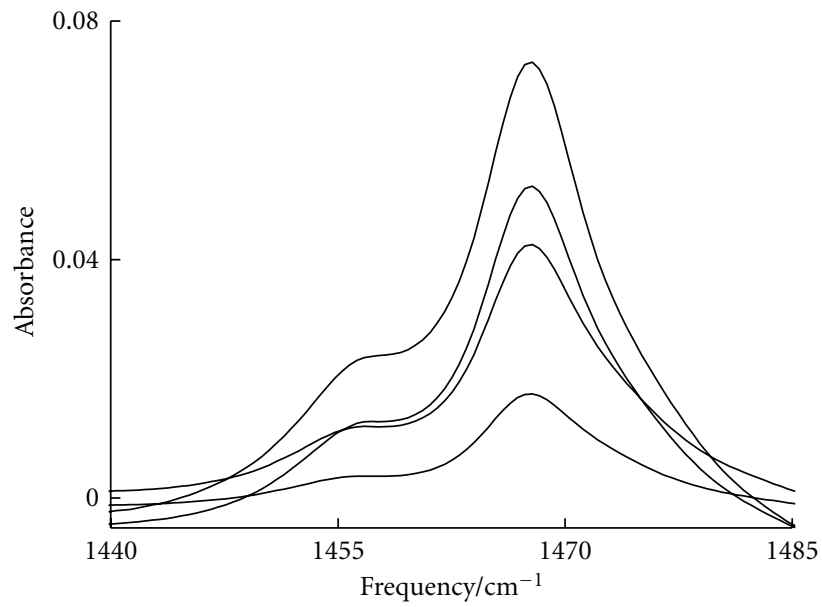

(b)

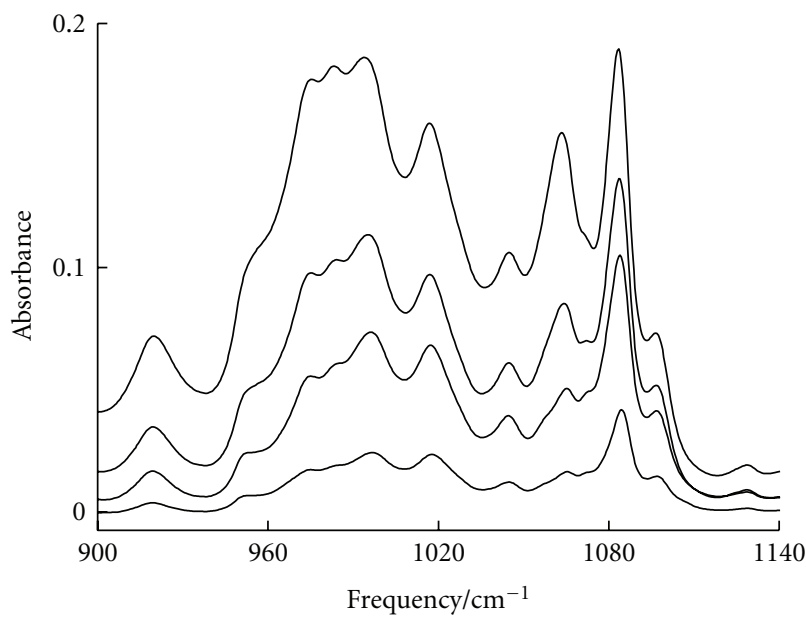

(d)

Figure 1: Selected regions of the FTIR spectra for the SDS molecule: (a) C-H stretching vibrational features; (b) methylene scissoring vibrational mode; (c) and (d) sulfate asymmetric and symmetric stretching bands, respectively. The spectra refer to the SDS packing densities: $1.2 \times 10^{15} ; 4.8 \times 10^{15} ; 3.5 \times 10^{16} ; 4.3 \times 10^{17}$ molecules $\mathrm{cm}^{-2}$.

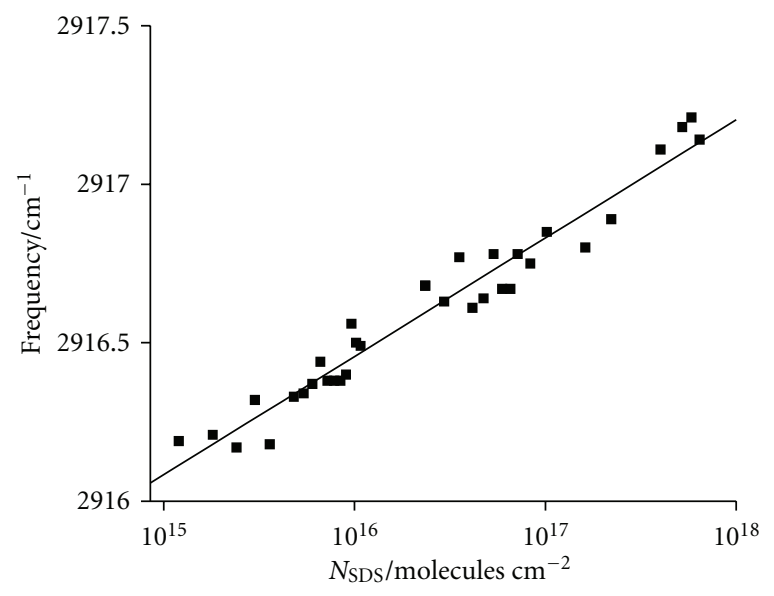

(a)

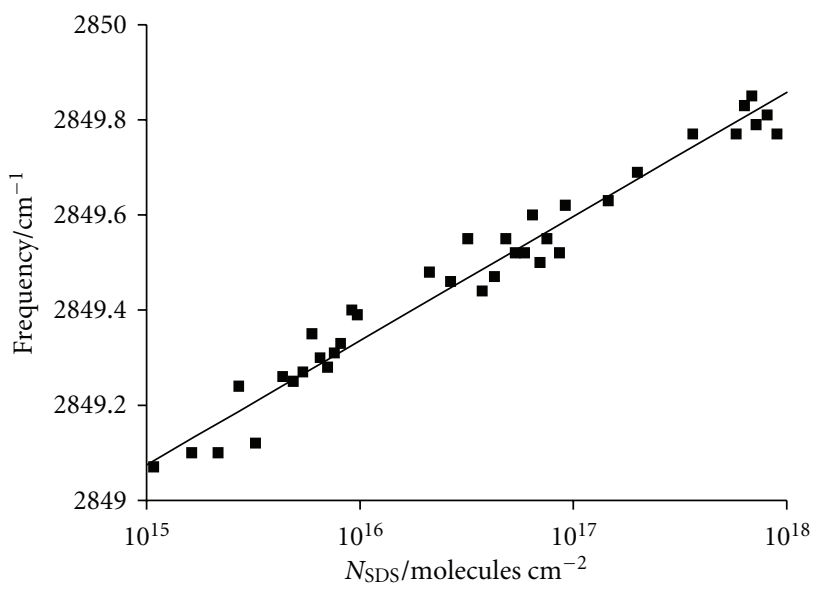

(b)

FIgURE 2: The $\mathrm{CH}_{2}$ asymmetric (a) and symmetric (b) stretching features for different SDS packing densities. 


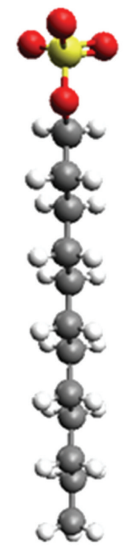

(a)

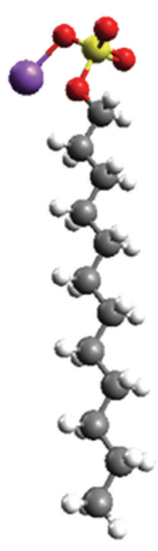

(b)

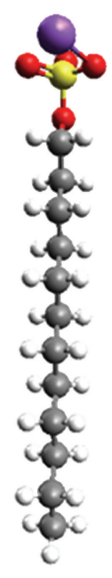

(c)

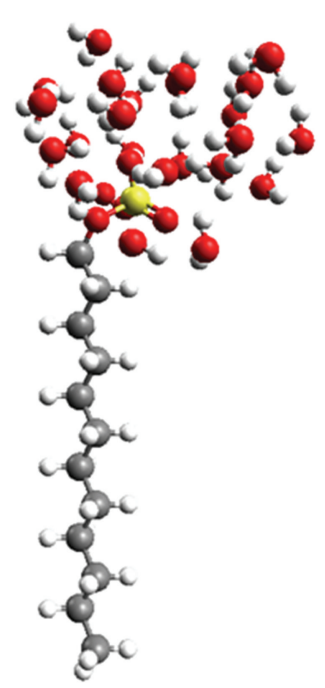

(d)

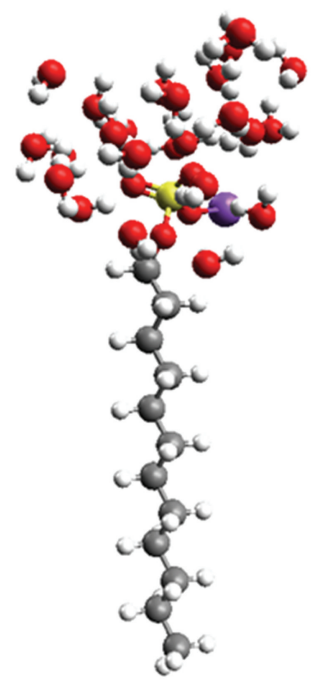

(e)

Figure 3: Structures optimized for dodecylsulfate. The structure (a) refers to the molecule without the Na counterion, while (b) and (c) consider the interaction with sodium. The structures (d) and (e) refer to the structure of the hydrated headgroup with and without the counterion, respectively.

conformation which ranges from 27 to $29 \mathrm{~cm}^{-1}$. However, the value observed in our study is lower than those predicted to the bulk $\left(39-48 \mathrm{~cm}^{-1}\right)[6,38,39]$ and liquid crystals (32$33 \mathrm{~cm}^{-1}$ ) [39-41]. If there is an SDS interaction with charge particles, it is observed a splitting between $33-38 \mathrm{~cm}^{-1}$ [42].

The dipole components of sulfate headgroup have been used to evaluate the horizontal and vertical effects over the molecules. While the band at $1219 \mathrm{~cm}^{-1}$ is assigned to the $A$ component, the band at $1249 \mathrm{~cm}^{-1}$ and the $\mathrm{SO}_{2}$ symmetric stretching band $\left(v_{\text {sym }}\left(\mathrm{SO}_{2}\right)\right)$ are associated to the $E$ component. It is important to mention that the directions of the dipole components are orthogonal to each other $[43,44]$ as it was confirmed by our theoretical calculations. Li and Tripp [43] suggested that the relation between the $v_{\mathrm{as}}\left(\mathrm{SO}_{2}\right)$ band intensities made allusion to important insights about the lateral electrostatic headgroup interaction. They indicated that the observation of an intensity band in $1249 \mathrm{~cm}^{-1}$ higher than that one in $1219 \mathrm{~cm}^{-1}$ may be an indicative of strong head-to-head lateral interaction. Nevertheless, the $\mathrm{I}_{1219 / 1249}$ ratio is basically constant and independent of the SDS packing density. A shoulder at $1278 \mathrm{~cm}^{-1}$ became more visible with the increase in the SDS packing density. This shoulder is associated with $E$ component of dipole moment, which is related to lateral interactions of the SDS headgroup. Therefore, this may be due to the repulsion between the lateral headgroup.

An important aspect about the $\mathrm{SO}_{2}$ symmetric vibrational feature is its observation at $1084 \mathrm{~cm}^{-1}$. Scheuing and Weers [11] observed the $v_{\text {sym }}\left(\mathrm{SO}_{2}\right)$ mode shifted to $1060 \mathrm{~cm}^{-1}$. The explanation for this shift is the loss of interaction between the headgroup and counterions, which is assessed by our quantum chemical calculations.

Two shoulders at 1097 and $1066 \mathrm{~cm}^{-1}$ are also observed. Some studies suggest that these two peaks may be due to the packing organization [39]. The intensity ratio between these two peaks $\left(\mathrm{I}_{1097 / 1066}\right)$ decreases from 5.88 at the packing density $1.2 \times 10^{15}$ molecules $\mathrm{cm}^{-2}$ to 0.85 at $4.3 \times$ $10^{17}$ molecules $\mathrm{cm}^{-2}$. In addition, the sharp bands at 1017 , 993 , and $983 \mathrm{~cm}^{-1}$ may be due to a crystalline phase, as it was reported previously by Sperline and Song [39].

Some studies suggest that the $v_{\mathrm{sym}}\left(\mathrm{SO}_{2}\right)$ mode changes in the presence of cationic surfactants $[11,43]$ or charged particles $[42,44]$. Using the B3LYP/6-311++G(d,p) method, it was possible to determine that the frequencies of the $v_{\text {sym }}\left(\mathrm{SO}_{2}\right)$ mode in the presence of $\mathrm{Na}^{+}$counterion are reduced in about $30 \mathrm{~cm}^{-1}$, as compared with the absence of $\mathrm{Na}^{+}$counterion (see Figure 3). Using semiempirical methods, the frequencies of the $v_{\mathrm{sym}}\left(\mathrm{SO}_{2}\right)$ mode in the presence of $\mathrm{Na}^{+}$counterion are reduced in 16 and $81 \mathrm{~cm}^{-1}$ using the AM1 and PM6 semiempirical methods, respectively. Some simulations using the AM1 semiempirical method were performed in order to describe the hydrated headgroup with 24 water molecules without $\mathrm{Na}^{+}$counterion and with $\mathrm{Na}^{+}$counterion. It is observed an increase of $120 \mathrm{~cm}^{-1}$ for the $v_{\text {sym }}\left(\mathrm{SO}_{2}\right)$ mode in the presence of $\mathrm{Na}^{+}$counterion. On the other hand, it is calculated a decrease of only $10 \mathrm{~cm}^{-1}$ in the presence of water.

\subsection{Cationic Surfactants}

3.3.1. $\mathrm{C}-\mathrm{H}$ Stretching Region. The vibrational frequencies of the $\mathrm{CTAB}$ molecule in the $\mathrm{C}-\mathrm{H}$ stretching region are shown in Figure 5(a). The $v_{\text {as }}\left(\mathrm{CH}_{3}\right)$ and $v_{\text {sym }}\left(\mathrm{CH}_{3}\right)$ frequencies are observed in 2943 and $2870 \mathrm{~cm}^{-1}$, respectively. The $v_{\mathrm{as}}\left(\mathrm{CH}_{3}\right)$ feature located in a frequency lower than $2956 \mathrm{~cm}^{-1}$ is an indicative of the crystalline structure. The $\mathrm{CH}_{3}$ asymmetric stretching mode presents a value $12 \mathrm{~cm}^{-1}$ smaller than that observed for the SDS molecule. On the other hand, the 


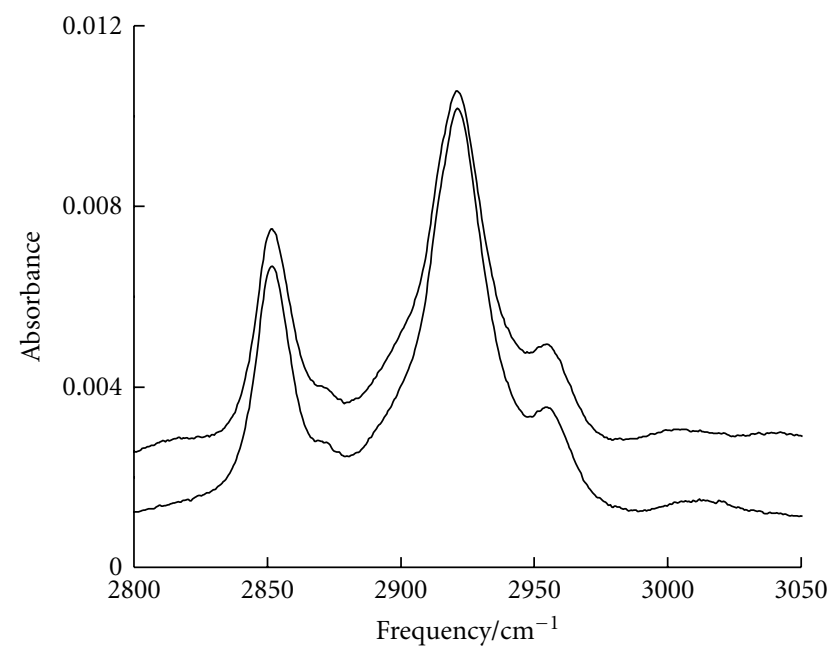

(a)

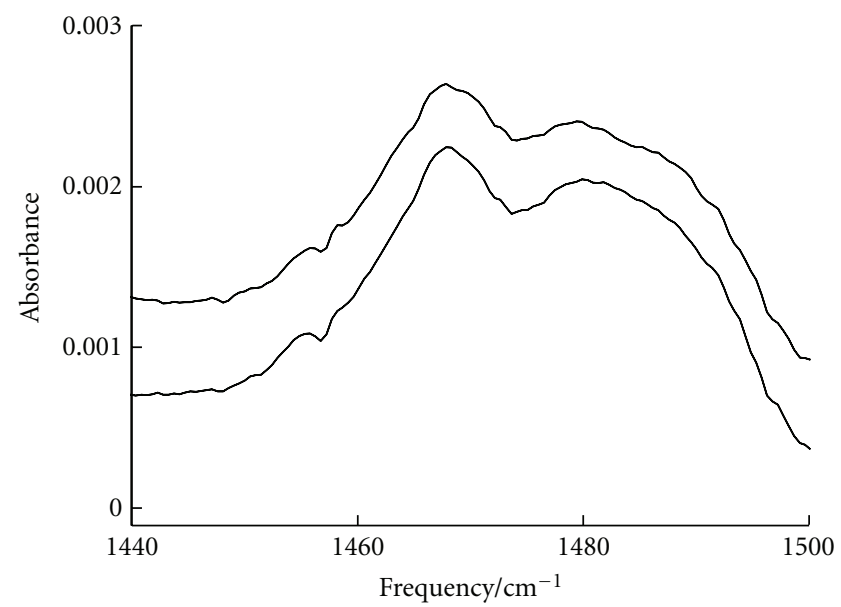

(c)

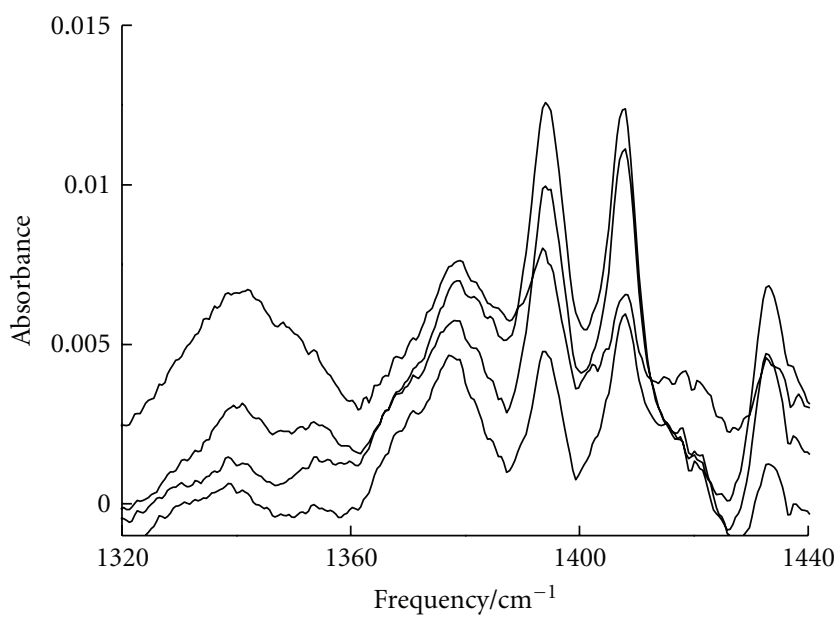

(e)

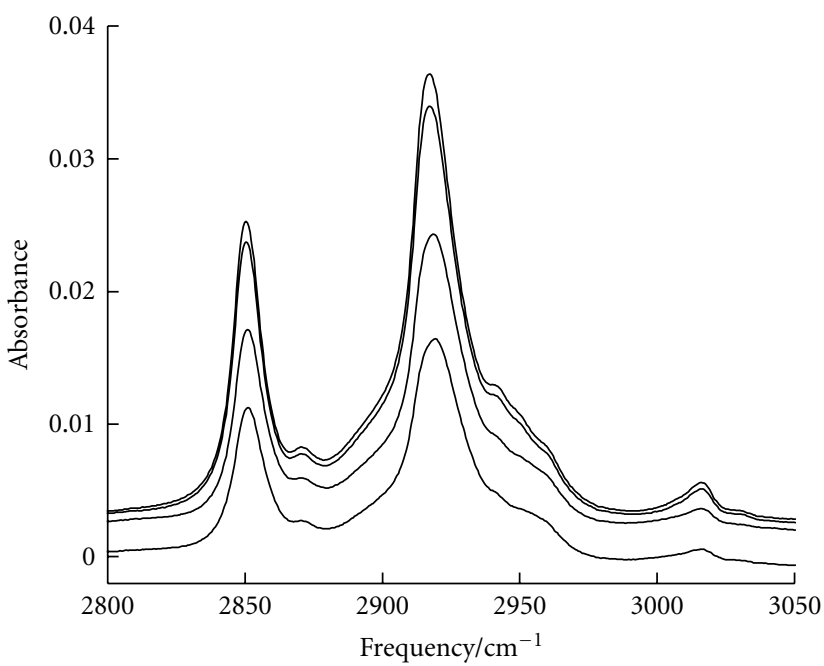

(b)

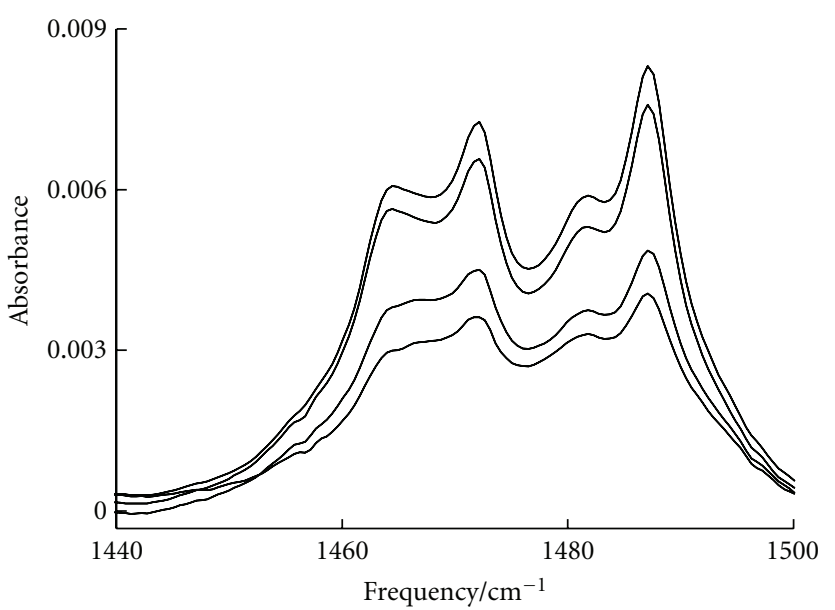

(d)

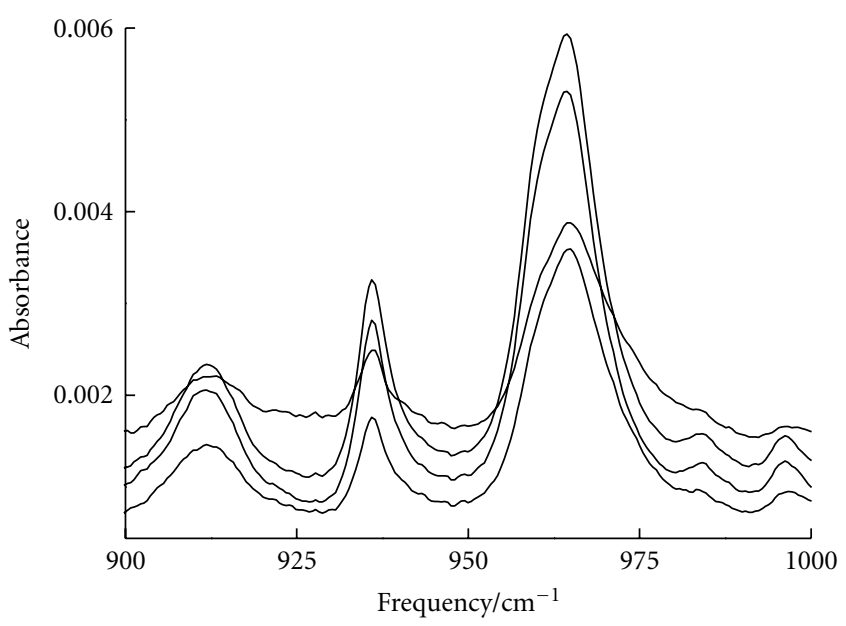

(f)

FIGURE 4: Selected regions of the FTIR spectra for the DTAB molecule. (a, b) C-H stretching vibrational features; (c, d) methylene scissoring

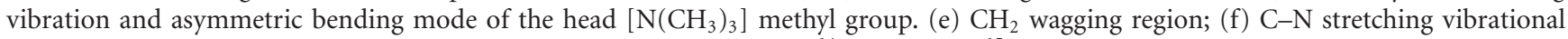
modes. (a) and (b) spectra refer to the DTAB packing densities: $9.6 \times 10^{14}$ and $1.2 \times 10^{15}$ molecules cm $^{-2}$, respectively. (b), (d), (e), and (f) spectra refer to the DTAB packing densities: $3.6 \times 10^{15}, 4.8 \times 10^{15}, 6.2 \times 10^{16}$, and $7.2 \times 10^{16}$ molecules $^{-2}$, respectively. 


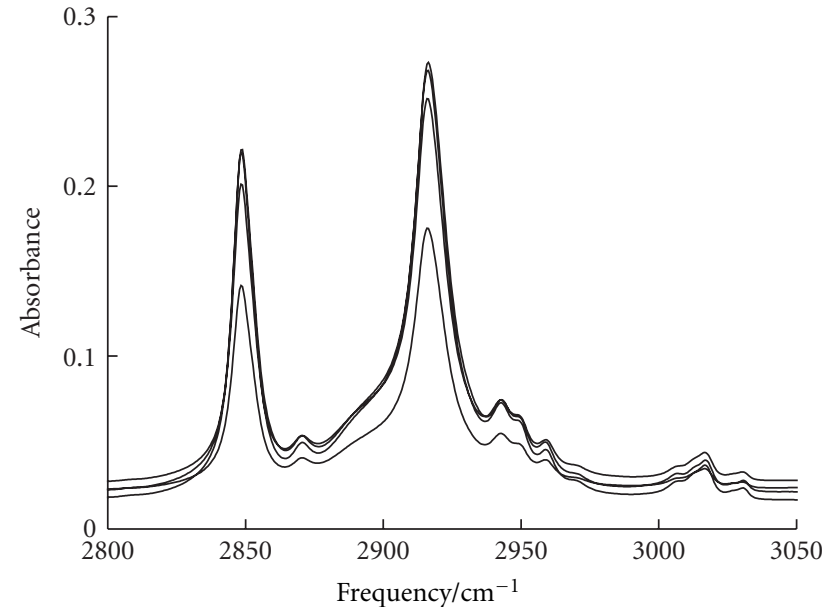

(a)

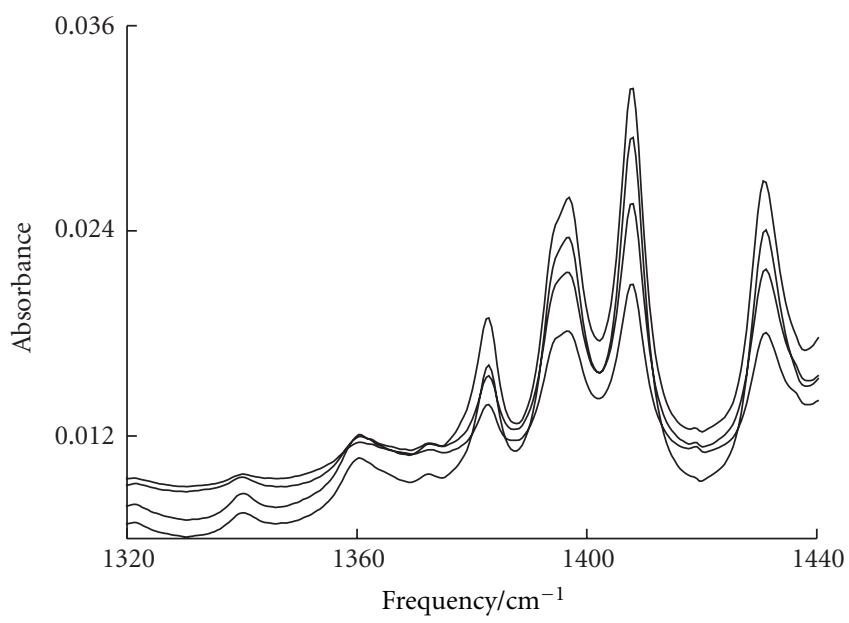

(c)

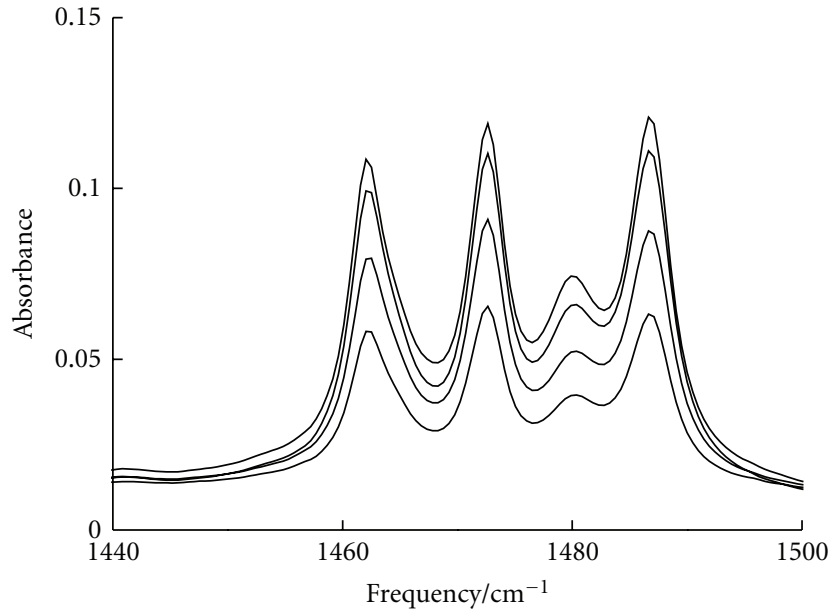

(b)

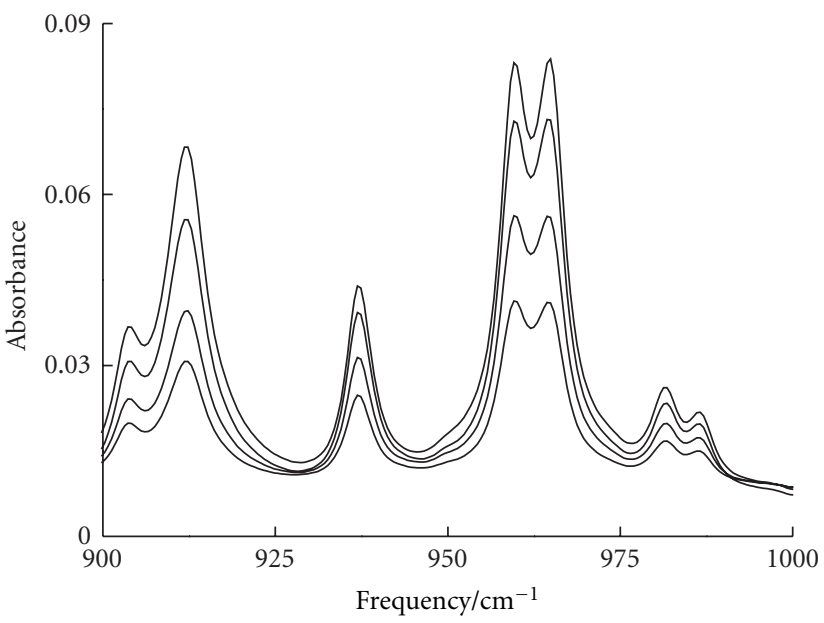

(d)

FIGURE 5: Selected regions of the FTIR spectra for the CTAB molecule. (a) C-H stretching vibrational features; (b) methylene scissoring

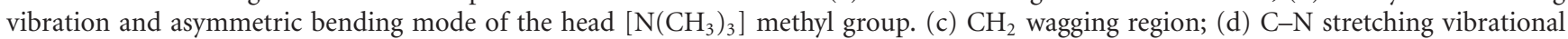

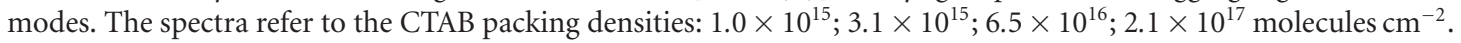

$v_{\text {sym }}\left(\mathrm{CH}_{3}\right)$ mode is only $3 \mathrm{~cm}^{-1}$ lower than that found for the SDS molecule, in agreement with the results reported in the literature [45]. It is important to assign that these bands seem to be less significant.

The $v_{\text {as }}\left(\mathrm{CH}_{3}\right)$ and $v_{\text {sym }}\left(\mathrm{CH}_{3}\right)$ bands of the DTAB molecule are difficult to be observed due to their lower intensities. It is only possible to detect them with packing densities larger than $10^{15}$ molecules $\mathrm{cm}^{-2}$. It is important to mention that it is also difficult to distinguish between $v_{\mathrm{as}}\left(\mathrm{CH}_{3}\right)$ and $v_{\text {sym }}\left(\mathrm{N}-\mathrm{CH}_{3}\right)$ bands, observing only a large band with low intensity in the region between 2940 and $2975 \mathrm{~cm}^{-1}$.

The shift in the $v_{\text {as }}\left(\mathrm{CH}_{2}\right)$ vibrational mode for the DTAB molecule is also observed. Figure 6(a) presents the behavior of the $v_{\text {as }}\left(\mathrm{CH}_{2}\right)$ feature for the DTAB molecule as the packing density increases. The $v_{\text {as }}\left(\mathrm{CH}_{2}\right)$ vibrational band shifts from 2921 to $2916.5 \mathrm{~cm}^{-1}$ for the DTAB molecule. The $\mathrm{CH}_{2}$ symmetric stretching $v_{\text {sym }}\left(\mathrm{CH}_{2}\right)$ shifts $2 \mathrm{~cm}^{-1}$ as presented in Figure 6(b). Therefore, there is an increase of all-trans conformers on the methylene chain and a decrease of gauche ones.

Figure 5(a) shows that the $v_{\mathrm{as}}\left(\mathrm{CH}_{2}\right)$ feature for the CTAB molecule is lower than $2917 \mathrm{~cm}^{-1}$ and the $\gamma_{\text {sym }}\left(\mathrm{CH}_{2}\right)$ frequency is lower than $2849 \mathrm{~cm}^{-1}$, meaning that it is a crystalline phase, which distinguishes from a micelle conformation [46, 47]. Figures 6(c) and 6(d) present straight lines for the changes of $v_{\text {as }}\left(\mathrm{CH}_{2}\right)$ and $v_{\text {sym }}\left(\mathrm{CH}_{2}\right)$ with the packing density of the CTAB molecule. Li et al. [48] also determined a similar frequency for the $v_{\text {as }}\left(\mathrm{CH}_{2}\right)$ feature. Nevertheless, several investigations have found values around $2918 \mathrm{~cm}^{-1}[45,49-52]$. It is important to mention that Campbell et al. [53] observed a $v_{\text {as }}\left(\mathrm{CH}_{2}\right)$ frequency lower than that found in our study, $2915 \mathrm{~cm}^{-1}$, for a packing density of $2.1 \times 10^{14}$ molecules $\mathrm{cm}^{-2}$, which is 3 times smaller than our lowest packing density. Considering the frequencies presented here, it is possible to assume that CTAB may follow the same behavior found for the SDS molecule. 


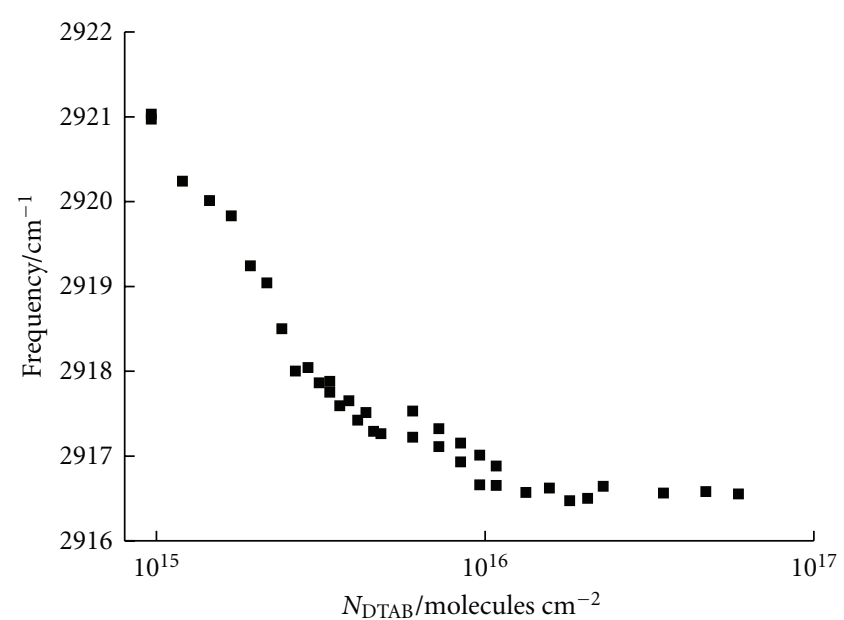

(a)

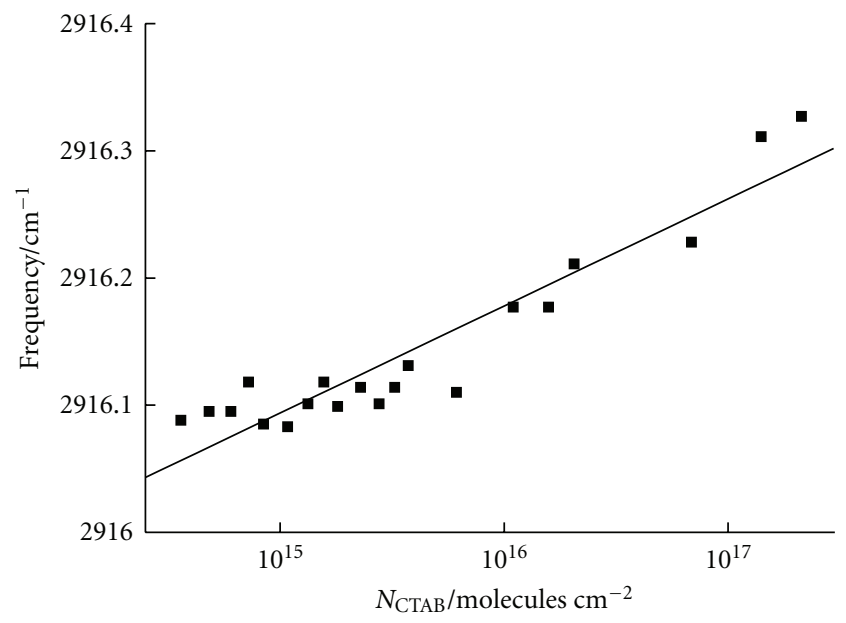

(c)

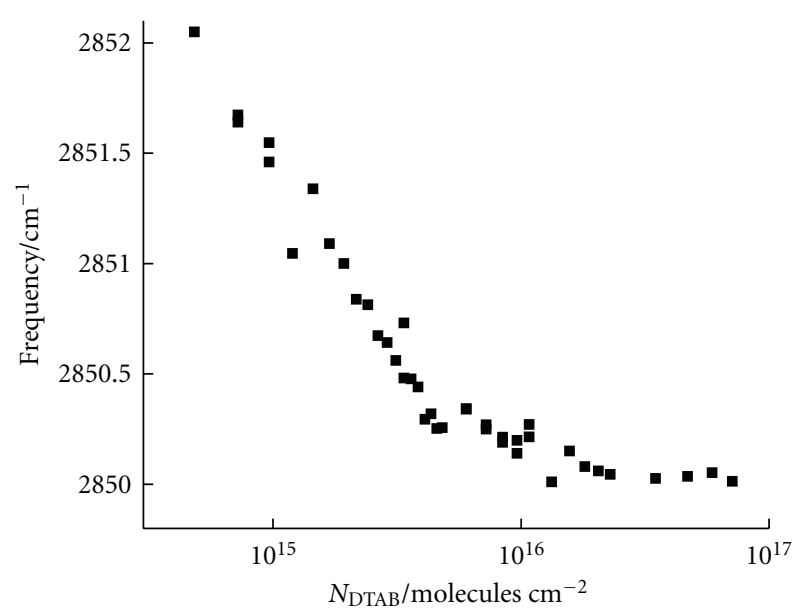

(b)

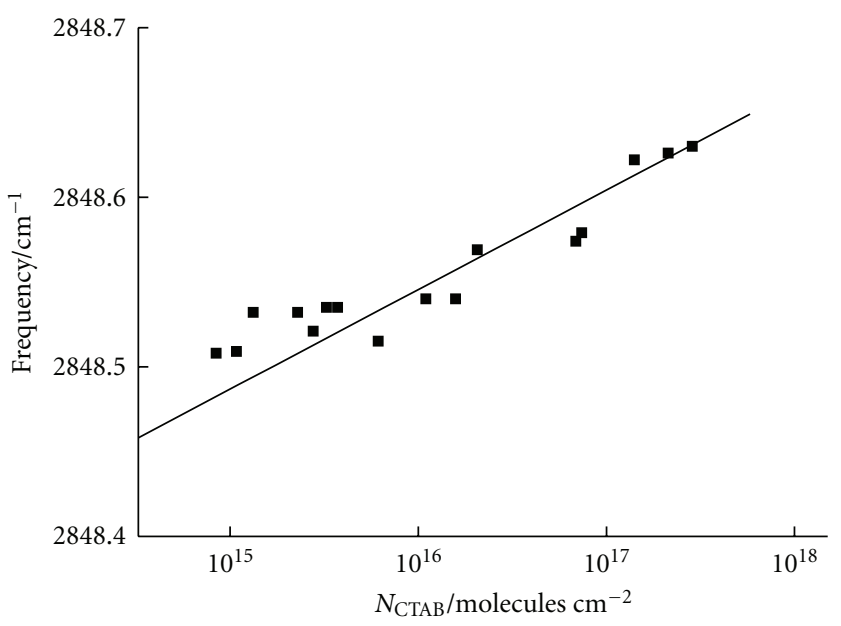

(d)

FIgURE 6: The $\mathrm{CH}_{2}$ asymmetric and symmetric stretching features for different SDS packing densities. (a) and (b) refer to the $v_{\text {as }}\left(\mathrm{CH}_{2}\right)$ and $v_{\text {sym }}\left(\mathrm{CH}_{2}\right)$ modes, respectively, for the DTAB molecule. (c) and (d) represent the $v_{\text {as }}\left(\mathrm{CH}_{2}\right)$ and $v_{\text {sym }}\left(\mathrm{CH}_{2}\right)$ modes, respectively, for the CTAB molecule.

3.3.2. $\mathrm{CH}_{2}$ Scissoring Region. The $\delta\left(\mathrm{CH}_{2}\right)$ scissoring feature for the $\mathrm{CTAB}$ molecule does not present any change with the increase of packing density as shown in Figure 5(b). The 1462 and $1472 \mathrm{~cm}^{-1}$ features are related to the $\delta\left(\mathrm{CH}_{2}\right)$ mode. However, the 1480 and $1487 \mathrm{~cm}^{-1}$ bands are characteristics of the $\delta_{\mathrm{as}}\left(\mathrm{N}-\mathrm{CH}_{3}\right)$ mode. When the $\delta\left(\mathrm{CH}_{2}\right)$ band is observed at $1472 \mathrm{~cm}^{-1}$, it is an indicative of high organization of the $\mathrm{CH}_{2}$ chain conformation. Another important aspect is the split of the $\delta\left(\mathrm{CH}_{2}\right)$ band. This is mainly due to the lateral interchain interaction between $\mathrm{CH}_{2}$ groups of adjacent chains, which in general characterizes an orthorhombic arrangement of the $\mathrm{CH}_{2}$ chains. It is important to mention that this splitting is absent in the monoclinic and triclinic conformation, or even in alkane chain assemblies of low packing density when lateral interchain interactions are weak $[8,54]$. The splitting of the $\delta\left(\mathrm{CH}_{2}\right)$ band has also been determined in other studies for the CTAB molecule in crystalline phases [45, 49-51].
The $\delta\left(\mathrm{CH}_{2}\right)$ mode for the DTAB molecule is observed at $1468 \mathrm{~cm}^{-1}$ as presented in Figure 4(c). Nevertheless, with the increase of the DTAB packing density, it is realized a splitting of this band in 1464 and $1472 \mathrm{~cm}^{-1}$ as shown in Figure 4(d). As it was previously mentioned, this mode is sensitive to the packing density arrangement in the alkyl chain assembly. The increase of trans conformers in the $\mathrm{CH}_{2}$ chain with the increase in the DTAB packing density is in agreement with the same observations found for the $v_{\text {as }}\left(\mathrm{CH}_{2}\right)$ and $v_{\text {sym }}\left(\mathrm{CH}_{2}\right)$ modes.

3.3.3. $\mathrm{CH}_{2}$ Wagging Region. For the DTAB and CTAB molecules, the wagging modes between $1300-1400 \mathrm{~cm}^{-1}$ is presented in Figures 4(e) and 5(c), respectively. The three bands for $C T A B$ are 1340,1360 , and $1370 \mathrm{~cm}^{-1}$. While the band with higher intensity in $1360 \mathrm{~cm}^{-1}$ refers to the $d-g$ conformations, the lower intensity band at $1370 \mathrm{~cm}^{-1}$ indicates a $g-t-g$ configuration. In addition, the band at $1340 \mathrm{~cm}^{-1}$ 


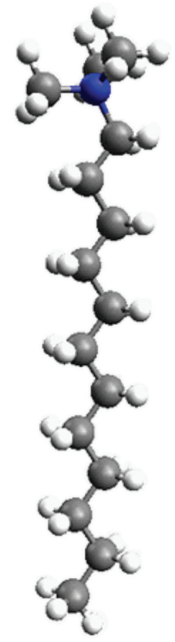

(a)

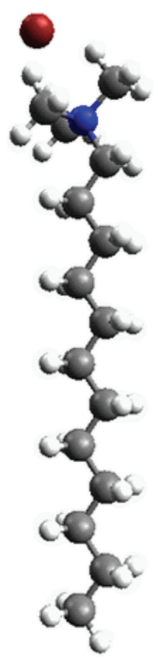

(b)

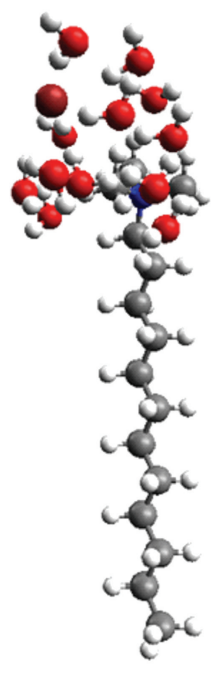

(c)
Figure 7: Optimized structures for the dodecyltrimethylammonium. The structure (a) refers to the molecule without the $\mathrm{Br}$ counterion, while (b) considers the interaction with bromine. The structure (c) refers to the structure of the hydrated headgroup with the counterion.

is an indication of an $e-g$ conformation. Venkataraman and Vasudevan [45] observed higher intensities for these modes, indicating an organization lower than that found in our study. For DTAB, it is detected only a broad band in $1360 \mathrm{~cm}^{-1}$, characteristic of a $d-g$ conformation. It was not observed any signal for densities lower than $3 \times 10^{15}$ DTAB molecules $\mathrm{cm}^{-2}$. Some authors commented that the absence of wagging signals is a strong evidence for the occurrence of a hydrocarbon chain melting phase transition [55-57]. Nevertheless, the main reason for the absence of peaks may be due to the low absorptivity of DTAB wagging region.

3.3.4. Headgroup Vibrational Region. For the CTAB molecules, none change is observed in the region of the headgroup vibrational features. The $v_{\text {sym }}\left(\mathrm{N}-\mathrm{CH}_{3}\right)$ feature appears as a shoulder of weak intensity in $2949 \mathrm{~cm}^{-1}$ and a very weak band in $2959 \mathrm{~cm}^{-1}$. As the CTAB packing density increases, there is a small enhancement of these two vibrational modes. While the degenerate $v_{\mathrm{as}}\left(\mathrm{N}-\mathrm{CH}_{3}\right)$ band splits into three peaks at 3009,3016 , and $3030 \mathrm{~cm}^{-1}$, the $\delta_{\text {sym }}\left(\mathrm{N}-\mathrm{CH}_{3}\right)$ and $\nu(\mathrm{C}-\mathrm{N})$ are observed at 1396 and $912 \mathrm{~cm}^{-1}$, respectively, which is in good agreement with the data in the literature [45].

The $\delta_{\mathrm{as}}\left(\mathrm{N}-\mathrm{CH}_{3}\right)$ mode of the DTAB molecule presents a different behavior as compared with what is observed for the CTAB molecule. The DTAB molecule has a large band in packing densities lower than $3 \times 10^{15}$ molecules $\mathrm{cm}^{-2}$. As the packing density increases, the $\delta_{\text {as }}\left(\mathrm{N}-\mathrm{CH}_{3}\right)$ feature splits in $7 \mathrm{~cm}^{-1}$, indicating a predominance of a trans conformation in the methylene chain. The splitting of the $\delta_{\mathrm{as}}\left(\mathrm{N}-\mathrm{CH}_{3}\right)$ band has been associated with differences in the headgroup packing. In general, it has also been linked with phase transitions in micelle structures [33]. Didodecyldimethylammonium (DDAB) bilayers also present a splitting of $7 \mathrm{~cm}^{-1}$ [33] in good agreement with our findings. Nevertheless, DTAB [33] and hexadecyltrimethylammonium sulfate micelles [32] showed a splitting of $11 \mathrm{~cm}^{-1}$.

The appearance of two bands for the $\delta_{\mathrm{as}}\left(\mathrm{N}-\mathrm{CH}_{3}\right)$ mode has also been correlated with a fully hydrated surfactant headgroup, or even related with the interaction of hydrated counterions in this region [33]. In order to understand the behavior of the bands $\delta_{\text {sym }}\left(\mathrm{N}-\mathrm{CH}_{3}\right)$ and $\delta_{\text {as }}\left(\mathrm{N}-\mathrm{CH}_{3}\right)$, some theoretical calculations were performed (see Figure 7). Our AM1 semiempirical calculations show that the presence of counterion in a hydrated headgroup yield a splitting not only for the $\delta_{\text {as }}\left(\mathrm{N}-\mathrm{CH}_{3}\right)$ mode, but also for the $\delta_{\text {sym }}(\mathrm{N}-$ $\mathrm{CH}_{3}$ ) feature. From our AM1 calculations it is observed a splitting of 26 and $30 \mathrm{~cm}^{-1}$ for $\delta_{\mathrm{as}}\left(\mathrm{N}-\mathrm{CH}_{3}\right)$ and $\delta_{\text {sym }}(\mathrm{N}-$ $\left.\mathrm{CH}_{3}\right)$ features, respectively. However, it was not possible to consider the hydrated headgroup in the absence of counterion due to some difficulty to find the stationary point with the AM1 method. In addition, the DFT results for the $\delta_{\text {sym }}\left(\mathrm{N}-\mathrm{CH}_{3}\right)$ mode is more sensitive for the $\delta_{\mathrm{as}}\left(\mathrm{N}-\mathrm{CH}_{3}\right)$ band to the interaction of $\mathrm{Br}^{-}$counterion. While the $\delta_{\mathrm{as}}(\mathrm{N}-$ $\left.\mathrm{CH}_{3}\right)$ mode shifts only $2 \mathrm{~cm}^{-1}$, the $\delta_{\text {sym }}\left(\mathrm{N}-\mathrm{CH}_{3}\right)$ mode shifts $20 \mathrm{~cm}^{-1}$.

As it can be observed in Figures 4(a), 4(e), and 4(f), the $v_{\mathrm{as}}\left(\mathrm{N}-\mathrm{CH}_{3}\right)$ feature for the DTAB molecule shows only one peak at $3016 \mathrm{~cm}^{-1}$, while the $\delta_{\text {sym }}\left(\mathrm{N}-\mathrm{CH}_{3}\right)$ and $\nu(\mathrm{C}-\mathrm{N})$ bands are observed at 1394 and $911 \mathrm{~cm}^{-1}$, respectively. With the increasing of the packing density, and similar to CTAB molecule, it is detected only an enlargement of the intensities.

\subsection{Zwitterionic Surfactant}

3.4.1. $C-H$ Stretching Region. The bands of the alkyl chain for the HPS molecule are presented in Figure 8(a). The $v_{\text {as }}\left(\mathrm{CH}_{3}\right)$ and $v_{\text {sym }}\left(\mathrm{CH}_{3}\right)$ bands are observed in 2944 and $2873 \mathrm{~cm}^{-1}$, respectively. Nevertheless, the $v_{\mathrm{as}}\left(\mathrm{CH}_{3}\right)$ mode is not detected for the HPS molecule when the packing density is larger than $10^{17}$ molecules $\mathrm{cm}^{-2}$. For densities larger than that, it is observed only a peak in $2954 \mathrm{~cm}^{-1}$ related to the $v_{\text {sym }}\left(\mathrm{N}-\mathrm{CH}_{3}\right)$ mode. Besides, the fact that the $v_{\text {as }}\left(\mathrm{CH}_{3}\right)$ mode presents values lower than $2956 \mathrm{~cm}^{-1}$ is a good indicative of a crystalline conformation.

Different from the other surfactants evaluated in this study, a larger shift was found for the HPS zwitterionic surfactant. The $v_{\text {as }}\left(\mathrm{CH}_{2}\right)$ feature presented a shift from 2920 to $2923 \mathrm{~cm}^{-1}$. Therefore, the gauche conformers in the methylene chain seem to be detected in our investigation, even with low densities. As usual, the amount of gauche conformers increases when the packing density increases. This is particularly observed for the $v_{\text {sym }}\left(\mathrm{CH}_{2}\right)$ band, which shows a similar shift, almost $3 \mathrm{~cm}^{-1}$.

3.4.2. $\mathrm{CH}_{2}$ Scissoring Region. The $\delta\left(\mathrm{CH}_{2}\right)$ feature for the HPS molecule shows a different behavior from the other surfactants previously investigated here. The $\delta\left(\mathrm{CH}_{2}\right)$ band for the HPS molecule is the only one that shows a significant shift to higher frequencies. For example, for packing densities smaller than $10^{17}$ molecules $\mathrm{cm}^{-2}$, it is observed a signal at 


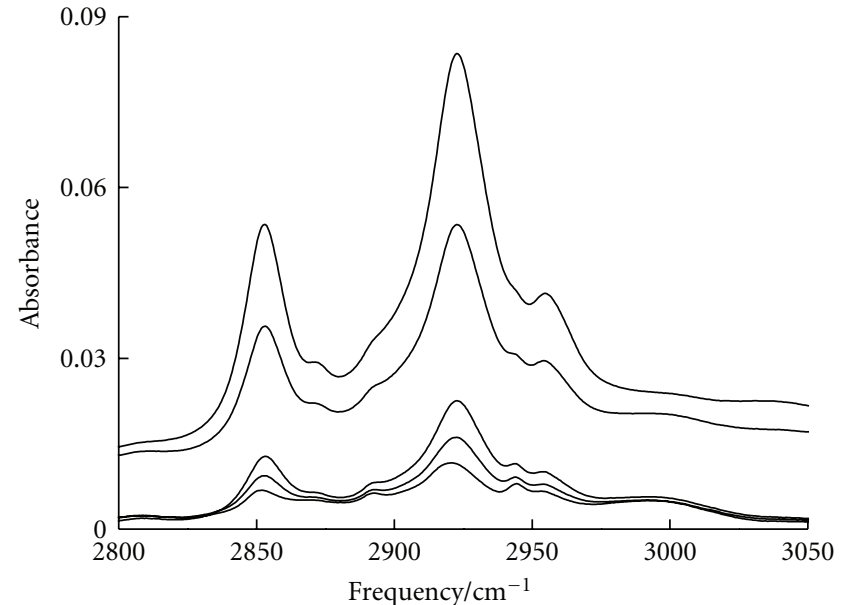

(a)

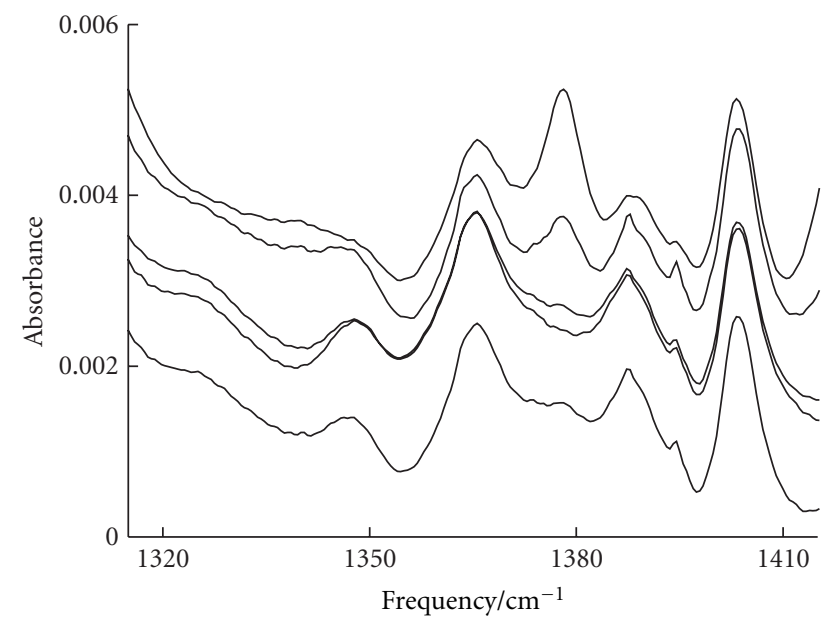

(c)

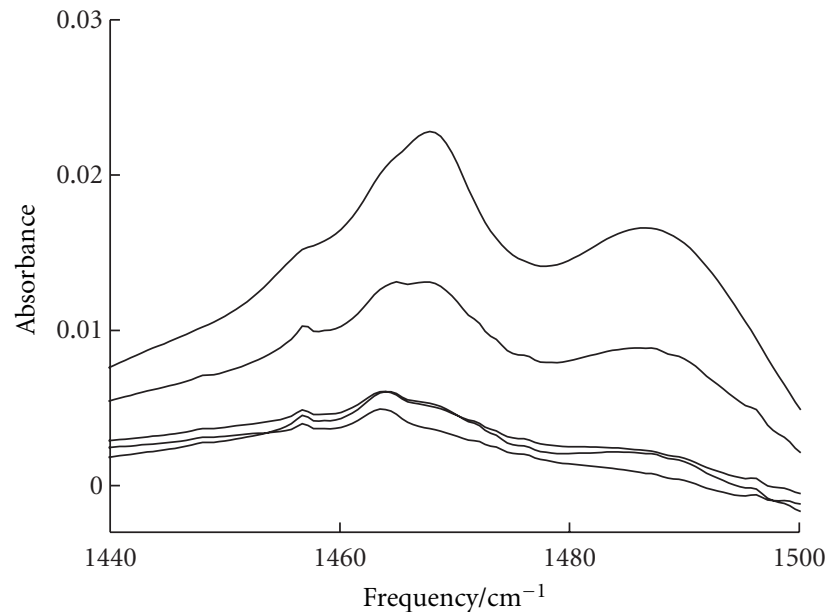

(b)

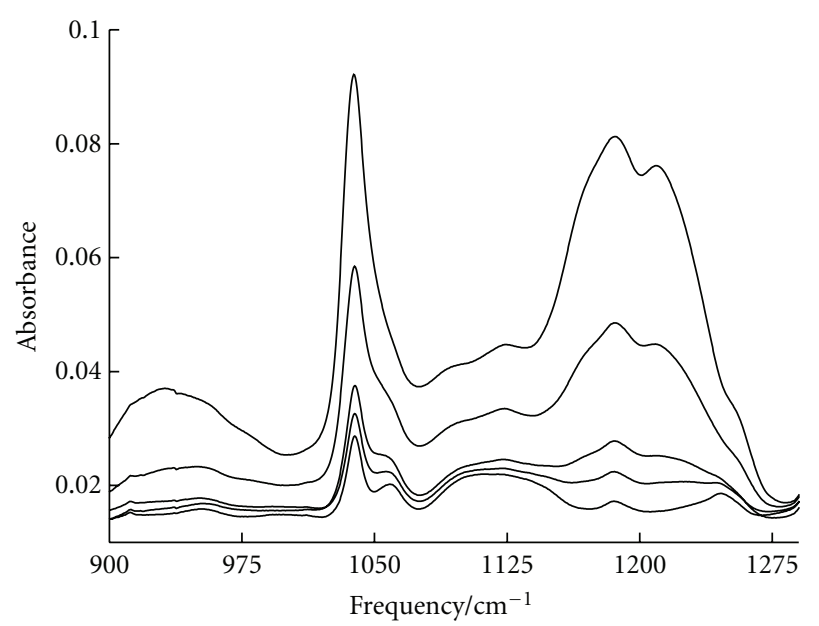

(d)

Figure 8: Selected regions of the FTIR spectra for the HPS molecule. (a) C-H stretching vibrational features; (b) methylene scissoring vibration and asymmetric bending mode of the head $\left.\left(\mathrm{N}_{(} \mathrm{CH}_{3}\right)_{3}\right)$ methyl group. (c) $\mathrm{CH}_{2}$ wagging region; (d) sulfonate vibrational modes.

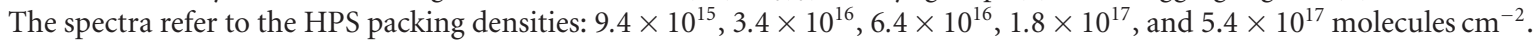

$1465 \mathrm{~cm}^{-1}$, which is shifted to $1468 \mathrm{~cm}^{-1}$ as presented in Figure $8(\mathrm{~b})$. This shift also indicates a high proportion of gauche conformations over the methylene chain.

Figure 9 presents the $\mathrm{CH}_{2}$ asymmetric (Figure 9(a)) and symmetric stretching (Figure 9(b)) features, and the $\mathrm{CH}_{2}$ scissoring mode (Figure 9(c)) for different HPS packing densities. The $\mathrm{CH}_{2}$ asymmetric stretching and the $\mathrm{CH}_{2}$ scissoring modes are linearly dependent on the HPS packing density. Surprisingly, the $\mathrm{CH}_{2}$ symmetric feature is not linearly dependent on the HPS density packing. Unfortunately, any plausible explanation for this behavior is available.

3.4.3. $\mathrm{CH}_{2}$ wagging region. The $1300-1400 \mathrm{~cm}^{-1}$ region is characteristic of wagging deformations that can be observed in Figure 8(c). The large band in $1345 \mathrm{~cm}^{-1}$ refers to the $e$ $g$ conformation, while the $1366 \mathrm{~cm}^{-1}$ peak is associated with $d$-g ones. Nevertheless, the $d-g$ conformers are only observed for packing densities larger than $10^{17}$ molecules $\mathrm{cm}^{-2}$.
Besides, the 1378 and $1402 \mathrm{~cm}^{-1}$ bands are associated with $\mathrm{CH}_{2}$ umbrella mode and $\delta_{\text {sym }}\left(\mathrm{N}-\mathrm{CH}_{3}\right)$, respectively.

3.4.4. Headgroup Vibrational Region. None change is observed for the $\delta_{\text {sym }}\left(\mathrm{N}-\mathrm{CH}_{3}\right)$ and $\nu_{\text {sym }}\left(\mathrm{N}-\mathrm{CH}_{3}\right)$ features for the HPS molecule, similar to CTAB and DTAB molecules. It was not possible to assign the $v_{\text {as }}\left(\mathrm{N}-\mathrm{CH}_{3}\right)$ band of the HPS molecule, perhaps due to its lower absorptivity. The feature located at $912 \mathrm{~cm}^{-1}$ is a small intensity and broad band, which refers to the $v(\mathrm{C}-\mathrm{N})$ stretching. Nevertheless, the $v(\mathrm{C}-$ $\mathrm{N})$ mode is observed only for packing densities larger than $10^{16}$ molecules $\mathrm{cm}^{-2}$ as presented in Figure 8(d). With the increasing of packing density for the HPS molecule, it is only observed a broad band in the $900-1000 \mathrm{~cm}^{-1}$ region.

The $1133-1280 \mathrm{~cm}^{-1}$ region is associated with the $v_{\mathrm{as}}\left(\mathrm{SO}_{2}\right)$ band. For densities lower than $10^{16}$ molecules $\mathrm{cm}^{-2}$, it is detected a doublet in 1246 and $1185 \mathrm{~cm}^{-1}$. Nevertheless, for packing densities between $10^{16}$ and $10^{17}$ molecules $\mathrm{cm}^{-2}$, 


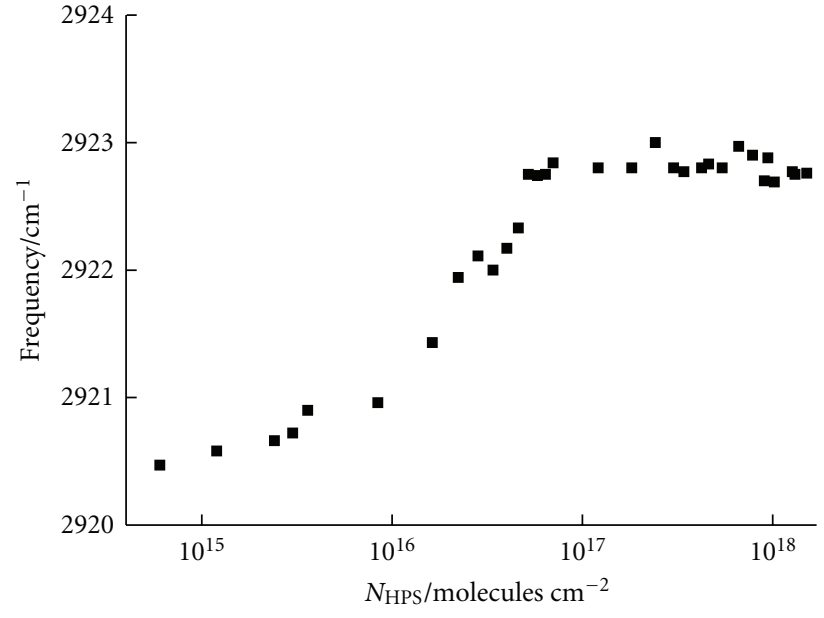

(a)

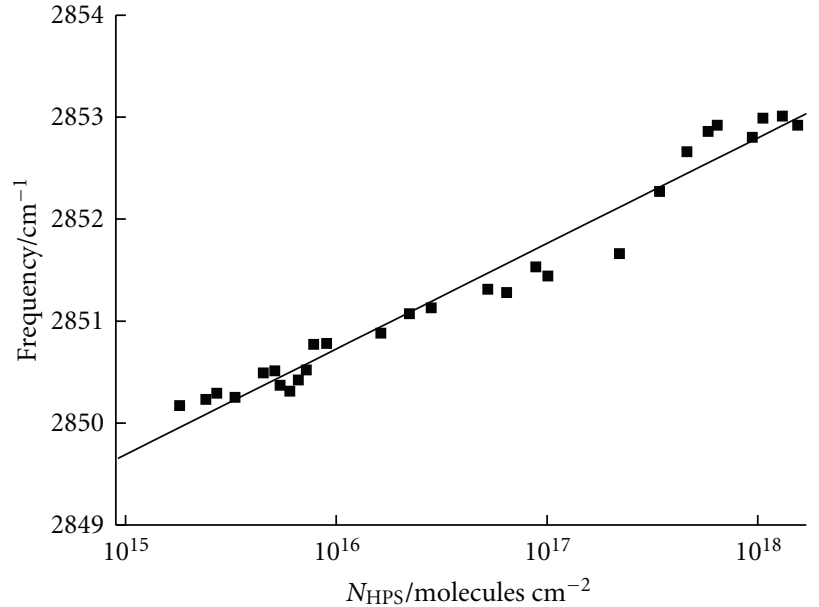

(b)

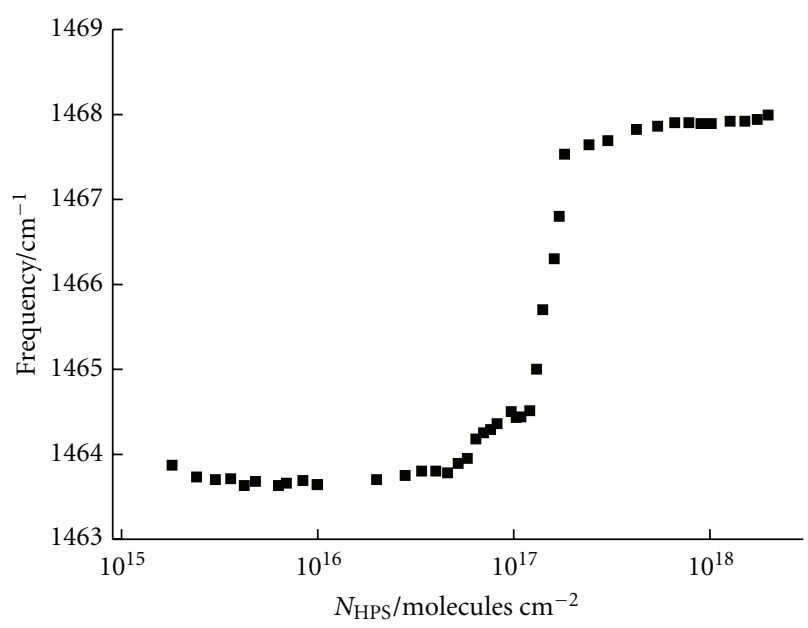

(c)

FIGURE 9: The $\mathrm{CH}_{2}$ asymmetric and symmetric stretching features for different HPS packing densities. (a) and (b) refer to the $\mathrm{CH}_{2}$ asymmetric and symmetric features, and (c) refers to the $\mathrm{CH}_{2}$ scissoring mode.

it is observed only one signal in $1185 \mathrm{~cm}^{-1}$, which shifts to $1186 \mathrm{~cm}^{-1}$ for densities larger than $10^{17}$ molecules $\mathrm{cm}^{-2}$. Furthermore, it appears two shoulders with small intensities in 1211 and $1255 \mathrm{~cm}^{-1}$. The absence of a doublet and appearance of a singlet are a clear indicative of a change from a crystalline (solid-like conformation), to a more disordered conformation (liquid-like environment) [58, 59]. Although it is observed a split of about $44 \mathrm{~cm}^{-1}$ in our study, methyl methanesulfonate and ethyl methanesulfonate present splits of 25 and $34 \mathrm{~cm}^{-1}$, respectively [58,59]. Furthermore, the frequencies of these shoulders for these molecules range from 1324 to $1367 \mathrm{~cm}^{-1}$, which are considerable higher than those found for the HPS molecule. Even higher frequencies for the $v_{\text {as }}\left(\mathrm{SO}_{2}\right)$ mode are also assigned for sulfonyl or sulfonic functional groups, which range from 1407 to $1456 \mathrm{~cm}^{-1}$ [6062].

The two features in 1038 and $1058 \mathrm{~cm}^{-1}$ are assigned to $v_{\text {sym }}\left(\mathrm{SO}_{2}\right)$ mode. For packing densities larger than $10^{17}$ molecules $\mathrm{cm}^{-2}$, it is observed only one strong band in $1038 \mathrm{~cm}^{-1}$. This reflects a change from a more ordered to a more disordered conformation. Despite the fact that there is a split of $20 \mathrm{~cm}^{-1}$, the doublet splits for methyl methanesulfonate and ethyl methanesulfonate are 7 and $11 \mathrm{~cm}^{-1}$, respectively $[58,59]$. It is also important to observe that these sulfonate groups present higher frequency values ranging from 1158 to $1183 \mathrm{~cm}^{-1}$, similar to those found for the asymmetric stretching. Considering the interaction of the sulfonate group with the hydronium ion, $\mathrm{H}_{3} \mathrm{O}^{+}$, DFT calculations presented a split of $18 \mathrm{~cm}^{-1}$ for the $v_{\text {sym }}\left(\mathrm{SO}_{2}\right)$ mode, which is in good agreement with a split of $10 \mathrm{~cm}^{-1}$ in experimental conditions [61].

\section{Conclusion}

The degree of ordering for anionic, cationic, and zwitterionic surfactants is investigated for different packing densities on Ge substrate by using FTIR-ATR spectroscopy. New spectroscopic insights on the conformational order of sodium dodecyl sulfate (SDS), N-hexadecyl-N-N-dimethyl-3-ammonio1-propane-sulfonate (HPS), hexadecyl-trimethylammonium 
bromide (CTAB), and dodecyl trimethylammonium bromide (DTAB) are presented. The effect of headgroup hydration and counterion was studied using DFT and semiempirical calculations. The $\mathrm{CH}_{2} v_{\text {asym }}$ and $v_{\text {sym }}$ features for the SDS molecule show a shift of 1.7 and $0.9 \mathrm{~cm}^{-1}$ to higher frequencies as the packing density increases, while it is observed a shift of 2.6 and $2.7 \mathrm{~cm}^{-1}$ for the HPS molecule, respectively. The DTAB molecule shows a shifted of $4.5 \mathrm{~cm}^{-1}$ to lower frequencies for both $\mathrm{CH}_{2} v_{\text {asym }}$ and $v_{\text {sym }}$ modes when the packing density increases. It is important to mention that these results are just a qualitative view of the organization of the alkyl chain conformation for each surfactant.

\section{Acknowledgments}

The authors are grateful to the FAPESP (grant no. 04/082275) and CNPq (grant no. 480631/2008-5) Brazilian agencies for the financial support. R. B. Viana also acknowledges $\mathrm{CNPq}$ for the fellowship. A. S. Pimentel thanks FAPERJ for an Award in the Jovem Cientista do Nosso Estado program (E-26/101.452/2010). A. S. Pimentel also thanks CNPq for the research support (grant no. 304187/2009-7 and 481481/ 2010-9). The authors are indebted to Professor Marcel Tabak (IQSC/USP) for the experimental and material support.

\section{References}

[1] M. J. Rosen, Surfactants and Interfacial Phenomena, WileyInterscience, New York, NY, USA, 3rd edition, 2004.

[2] M. Antonietti, "Surfactants for novel templating applications," Current Opinion in Colloid \& Interface Science, vol. 6, pp. 244248, 2001.

[3] E. J. Wanless and W. A. Ducker, "Organization of sodium dodecyl sulfate at the graphite-solution interface," Journal of Physical Chemistry, vol. 100, no. 8, pp. 3207-3214, 1996.

[4] D. Mobius and R. Miller, Organized Monolayers and Assemblies: Structure, Processes and Function, Elsevier, Amsterdam, The Netherlands, 2002.

[5] R. P. Sperline, "Infrared spectroscopic study of the crystalline phases of sodium dodecyl sulfate," Langmuir, vol. 13, no. 14, pp. 3715-3726, 1997.

[6] R. P. Sperline, Y. Song, and H. Freiser, "Temperature dependent structure of adsorbed sodium dodecyl sulfate at the $\mathrm{Al}_{2} \mathrm{O}_{3}$ /water interface," Langmuir, vol. 13, no. 14, pp. 37273732, 1997.

[7] R. G. Snyder, S. L. Hsu, and S. Krimm, "Vibrational spectra in the $\mathrm{CH}$ stretching region and the structure of the polymethylene chain," Spectrochimica Acta A, vol. 34, no. 4, pp. 395-406, 1978.

[8] C. R. Flach, J. W. Brauner, and R. Mendelsohn, "Calcium ion interactions with insoluble phospholipid monolayer films at the A/W interface. External reflection-absorption IR studies," Biophysical Journal, vol. 65, no. 5, pp. 1994-2001, 1993.

[9] A. Dicko, H. Bourque, and M. Pézolet, "Study by infrared spectroscopy of the conformation of dipalmitoylphosphatidylglycerol monolayers at the air-water interface and transferred on solid substrates," Chemistry and Physics of Lipids, vol. 96, no. 1-2, pp. 125-139, 1998.

[10] A. J. Prosser and E. I. Franses, "Infrared reflection absorption spectroscopy (IRRAS) of aqueous nonsurfactant salts, ionic surfactants, and mixed ionic surfactants," Langmuir, vol. 18, no. 24, pp. 9234-9242, 2002.
[11] D. R. Scheuing and J. G. Weers, "A Fourier transform infrared spectroscopic study of dodecyltrimethylammonium chloride/sodium dodecyl sulfate surfactant mixtures," Langmuir, vol. 6, no. 3, pp. 665-671, 1990.

[12] M. J. Vold and R. D. Vold, Colloid Chemistry, Reinhold, New York, NY, USA, 1964.

[13] G. B. Sigal, M. Mrksich, and G. M. Whitesides, "Using surface plasmon resonance spectroscopy to measure the association of detergents with self-assembled monolayers of hexadecanethiolate on gold," Langmuir, vol. 13, no. 10, pp. 2749-2755, 1997.

[14] A. J. Prosser and E. I. Franses, "Adsorption and surface tension of ionic surfactants at the air-water interface: review and evaluation of equilibrium models," Colloids and Surfaces A, vol. 178, no. 1-3, pp. 1-40, 2001.

[15] L. L. Norman and A. Badia, "Electrochemical surface plasmon resonance investigation of dodecyl sulfate adsorption to electroactive self-assembled monolayers via ion-pairing interactions," Langmuir, vol. 23, no. 20, pp. 10198-10208, 2007.

[16] I. J. Burgess, "Adsorption and aggregation of sodium dodecyl sulfate on $\mathrm{Au}(111)$ electrode surfaces," [M.S. thesis], University of Guelph, Ontario, Canada, 2000.

[17] I. Burgess, C. A. Jeffrey, X. Cai, G. Szymanski, Z. Galus, and J. Lipkowski, "Direct visualization of the potential-controlled transformation of hemimicellar aggregates of dodecyl sulfate into a condensed monolayer at the $\mathrm{Au}(111)$ electrode surface," Langmuir, vol. 15, no. 8, pp. 2607-2616, 1999.

[18] I. Burgess, V. Zamlynny, G. Szymanski et al., "Electrochemical and neutron reflectivity characterization of dodecyl sulfate adsorption and aggregation at the gold-water interface," Langmuir, vol. 17, no. 11, pp. 3355-3367, 2001.

[19] N. J. Harrick, Internal Reflection Spectroscopy, Harrick Scientific, New York, NY, USA, 1987.

[20] M. J. Frisch, G. W. Trucks, H. B. Schlegel et al., GAUSSIAN 03, Gaussian, Pittsburgh, Pa, USA, 2003.

[21] MOPAC2009 and J. J. P. Stewart, Stewart Computational Chemistry, Colorado Springs, Colo, USA, http://openmopac .net/, 2008.

[22] A. D. Becke, "Density-functional thermochemistry. III. The role of exact exchange," The Journal of Chemical Physics, vol. 98, no. 7, pp. 5648-5652, 1993.

[23] C. Lee, W. Yang, and R. G. Parr, "Development of the ColleSalvetti correlation-energy formula into a functional of the electron density," Physical Review B, vol. 37, no. 2, pp. 785789, 1988.

[24] M. J. S. Dewar, E. G. Zoebisch, E. F. Healy, and J. J. P. Stewart, "AM1: a new general purpose quantum mechanical molecular model," Journal of the American Chemical Society, vol. 107, no. 13, pp. 3902-3909, 1985.

[25] G. B. Rocha, R. O. Freire, A. M. Simas, and J. J. P. Stewart, "RM1: a reparameterization of AM1 for $\mathrm{H}, \mathrm{C}, \mathrm{N}, \mathrm{O}, \mathrm{P}, \mathrm{S}, \mathrm{F}, \mathrm{Cl}$, $\mathrm{Br}$, and I," Journal of Computational Chemistry, vol. 27, no. 10, pp. 1101-1111, 2006.

[26] J. J. P. Stewart, "Optimization of parameters for semiempirical methods V: modification of NDDO approximations and application to 70 elements," Journal of Molecular Modeling, vol. 13, no. 12, pp. 1173-1213, 2007.

[27] M. S. Akhter and S. M. Alawi, "Micellar behaviour of cetyltrimethylammonium bromide in N-methyl acetamide-alkanol and N,N-dimethyl acetamide-alkanol mixtures," Colloids and Surfaces A, vol. 196, no. 2-3, pp. 163-174, 2002.

[28] N. C. de Souza, J. R. Silva, M. A. Pereira-da-Silva et al., "Dynamic scale theory for characterizing surface morphology of layer-by-layer films of poly(o-methoxyaniline)," Journal of 
Nanoscience and Nanotechnology, vol. 4, no. 5, pp. 548-552, 2004.

[29] H. S. Silva, T. M. Uehara, K. Bergamaski, and P. B. Miranda, "Molecular ordering in layer-by-layer polyelectrolyte films studied by sum-frequency vibrational spectroscopy: the effects of drying procedures," Journal of Nanoscience and Nanotechnology, vol. 8, no. 7, pp. 3399-3405, 2008.

[30] T. J. Halthur, P. M. Claesson, and U. M. Elofsson, "Stability of polypeptide multilayers as studied by in situ ellipsometry: effects of drying and post-buildup changes in temperature and $\mathrm{pH}$," Journal of the American Chemical Society, vol. 126, no. 51, pp. 17009-17015, 2004.

[31] T. Kawai, H. Kamio, T. Kondo, and K. Kon-No, "Effects of concentration and temperature on SDS monolayers at the air-solution interface studied by infrared external reflection spectroscopy," Journal of Physical Chemistry B, vol. 109, no. 10, pp. 4497-4500, 2005.

[32] T. C. Wong, N. B. Wong, and P. A. Tanner, "A fourier transform IR study of the phase transitions and molecular order in the hexadecyltrimethylammonium sulfate/water system," Journal of Colloid and Interface Science, vol. 186, no. 2, pp. 325-331, 1997.

[33] J. G. Weers and D. R. Scheuing, "Structure/performance relationships in monoalkyl/dialkyl cationic surfactant mixtures," Journal of Colloid And Interface Science, vol. 145, no. 2, pp. 563-580, 1991.

[34] R. A. Vaia, R. K. Teukolsky, and E. P. Giannelis, "Interlayer structure and molecular environment of alkylammonium layered silicates," Chemistry of Materials, vol. 6, no. 7, pp. 1017-1022, 1994.

[35] J. G. Weers and D. R. Scheuing, "FTIR spectroscopy in colloid and interface science," in ACS Symposium Series 447, J. G. Weers and D. R. Scheuing, Eds., pp. 87-122, American Chemical Society, Washington, DC, 1990.

[36] R. G. Snyder, "Vibrational study of the chain conformation of the liquid n-paraffins and molten polyethylene," The Journal of Chemical Physics, vol. 47, no. 4, pp. 1316-1360, 1967.

[37] F. Holler and J. B. Callis, "Conformation of the hydrocarbon chains of sodium dodecyl sulfate molecules in micelles: an FTIR study," Journal of Physical Chemistry, vol. 93, no. 5, pp. 2053-2058, 1989.

[38] R. P. Sperline, Y. Song, and H. Freiser, "Fourier transform infrared attenuated total reflection spectroscopy linear dichroism study of sodium dodecyl sulfate adsorption at the $\mathrm{Al}_{2} \mathrm{O}_{3}$ /water interface using $\mathrm{Al}_{2} \mathrm{O}_{3}$-coated optics," Langmuir, vol. 8, no. 9, pp. 2183-2191, 1992.

[39] R. P. Sperline and Y. Song, "Temperature independent adsorbate structure of 4-octyl-, 4-decyl-, and 4-dodecylbenzenesulfonates at the $\mathrm{Al}_{2} \mathrm{O}_{3}$ /water interface," Langmuir, vol. 13, no. 26, pp. 6985-6994, 1997.

[40] T. Kawai, J. Umemura, and T. Takenaka, "Fourier-transform infrared study on the phase transitions of a sodium dodecyl sulfate-water system," Bulletin of the Institute for Chemical Research, Kyoto University, vol. 61, pp. 314-323, 1983.

[41] T. Kawai, H. Kamio, and K. Kon-No, "Infrared external reflection spectroscopy of sodium dodecyl sulfate monolayers at the air-solution interface: removal of bulk-phase water concentration effects," Langmuir, vol. 14, no. 18, pp. 4964-4966, 1998.

[42] K. D. Dobson, A. D. Roddick-Lanzilotta, and A. J. McQuillan, "In situ infrared spectroscopic investigation of adsorption of sodium dodecylsulfate and of cetyltrimethylammonium bromide surfactants to $\mathrm{TiO}_{2}, \mathrm{ZrO}_{2}, \mathrm{Al}_{2} \mathrm{O}_{3}$, and $\mathrm{Ta}_{2} \mathrm{O}_{5}$ particle films from aqueous solutions," Vibrational spectroscopy, vol. 24, no. 2, pp. 287-295, 2000.

[43] H. Li and C. P. Tripp, "Use of infrared bands of the surfactant headgroup to identify mixed surfactant structures adsorbed on Titania," Journal of Physical Chemistry B, vol. 108, no. 47, pp. 18318-18326, 2004.

[44] M. Machida, K. Kawamura, T. Kawano, D. Zhang, and K. Ikeue, "Layered Pr-dodecyl sulfate mesophases as precursors of $\mathrm{Pr}_{2} \mathrm{O}_{2} \mathrm{SO}_{4}$ having a large oxygen-storage capacity," Journal of Materials Chemistry, vol. 16, no. 30, pp. 3084-3090, 2006.

[45] N. V. Venkataraman and S. Vasudevan, "Conformation of methylene chains in an intercalated surfactant bilayer," Journal of Physical Chemistry B, vol. 105, no. 9, pp. 1805-1812, 2001.

[46] T. Kawai, J. Umemura, T. Takenaka, M. Kodama, and S. Seki, "Fourier transform infrared study on the phase transitions of an octadecyltrimethylammonium chloride-water system," Journal of Colloid And Interface Science, vol. 103, no. 1, pp. 5661, 1985.

[47] K. V. Padalkar, V. G. Gaikar, and V. K. Aswal, "Characterization of mixed micelles of sodium cumene sulfonate with sodium dodecyl sulfate and cetyl trimethylammonium bromide by SANS, FTIR spectroscopy and NMR spectroscopy," Journal of Molecular Liquids, vol. 144, no. 1-2, pp. 40-49, 2009.

[48] Z. Li, W. T. Jiang, and H. Hong, "An FTIR investigation of hexadecyltrimethylammonium intercalation into rectorite," Spectrochimica Acta A, vol. 71, no. 4, pp. 1525-1534, 2008.

[49] X. Yu, "The preparation and characterization of cetyltrimethylammonium intercalated muscovite," Microporous and Mesoporous Materials, vol. 98, no. 1-3, pp. 70-79, 2007.

[50] X. Yu, L. Zhao, X. Gao, X. Zhang, and N. Wu, "The intercalation of cetyltrimethylammonium cations into muscovite by a two-step process: II. The intercalation of cetyltrimethylammonium cations into Li-muscovite," Journal of Solid State Chemistry, vol. 179, no. 5, pp. 1525-1535, 2006.

[51] J. Zhu, H. He, L. Zhu, X. Wen, and F. Deng, "Characterization of organic phases in the interlayer of montmorillonite using FTIR and ${ }^{13} \mathrm{C}$ NMR," Journal of Colloid and Interface Science, vol. 286, no. 1, pp. 239-244, 2005.

[52] R. Zhu, T. Wang, F. Ge, W. Chen, and Z. You, "Intercalation of both CTMAB and $\mathrm{Al}_{13}$ into montmorillonite," Journal of Colloid and Interface Science, vol. 335, no. 1, pp. 77-83, 2009.

[53] R. A. Campbell, S. R. W. Parker, J. P. R. Day, and C. D. Bain, "External reflection FTIR spectroscopy of the cationic surfactant hexadecyltrimethylammonium bromide (CTAB) on an overflowing cylinder," Langmuir, vol. 20, no. 20, pp. 8740-8753, 2004.

[54] R. G. Snyder, "Vibrational spectra of crystalline n-paraffins: 2. Intermolecular effects," Journal of Molecular Spectroscopy, vol. 7, pp. 116-144, 1964.

[55] N. C. Chia and R. Mendelsohn, " $\mathrm{CH}_{2}$ wagging modes of unsaturated acyl chains as IR probes of conformational order in methyl alkenoates and phospholipid bilayers," Journal of Physical Chemistry, vol. 96, no. 25, pp. 10543-10547, 1992.

[56] N. C. Chia, C. Vilcheze, R. Bittman, and R. Mendelsohn, "Interactions of cholesterol and synthetic sterols with phosphatidylcholines as deduced from infrared $\mathrm{CH}_{2}$ wagging progression intensities," Journal of the American Chemical Society, vol. 115, no. 25, pp. 12050-12055, 1993.

[57] L. Senak, M. A. Davies, and R. Mendelsohn, "A quantitative IR study of hydrocarbon chain conformation in alkanes and phospholipids: $\mathrm{CH}_{2}$ wagging modes in disordered bilayer and HII phases," Journal of Physical Chemistry, vol. 95, no. 6, pp. 2565-2571, 1991. 
[58] M. E. Tuttolomondo, A. Navarro, T. Peña, E. L. Varetti, and A. Ben Altabef, "Theoretical structure and vibrational analysis of Ethyl methanesulfonate, $\mathrm{CH}_{3} \mathrm{SO}_{2} \mathrm{OCH}_{2} \mathrm{CH}_{3}$," Journal of Physical Chemistry A, vol. 109, no. 35, pp. 7946-7956, 2005.

[59] M. E. Tuttolomondo, A. Navarro, T. Peña, E. L. Varetti, S. F. Parker, and A. B. Altabef, "Conformational and vibrational analysis of methyl methanesulfonate, $\mathrm{CH}_{3} \mathrm{SO}_{2} \mathrm{OCH}_{3}$," Journal of Physical Chemistry A, vol. 113, no. 29, pp. 8401-8408, 2009.

[60] N. Idupulapati, R. Devanathan, and M. Dupuis, "Ab initio study of hydration and proton dissociation in ionomer membranes," Journal of Physical Chemistry A, vol. 114, no. 25, pp. 6904-6912, 2010.

[61] D. S. Warren and A. J. McQuillan, "Infrared spectroscopic and DFT vibrational mode study of perfluoro(2-ethoxyethane) sulfonic acid (PES), a model nafion side-chain molecule," Journal of Physical Chemistry B, vol. 112, no. 34, pp. 1053510543, 2008.

[62] S. P. Gejji, K. Hermansson, and J. Lindgren, "Ab initio vibrational frequencies of the triflic acid molecule," Journal of Physical Chemistry, vol. 97, no. 27, pp. 6986-6989, 1993. 


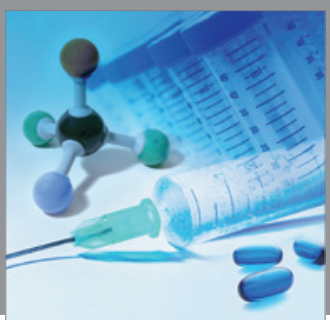

International Journal of

Medicinal Chemistry

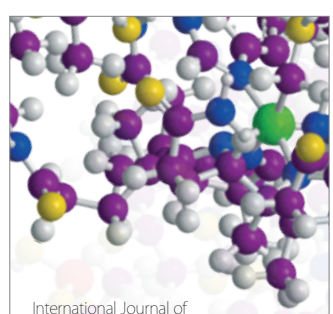

Carbohydrate Chemistry

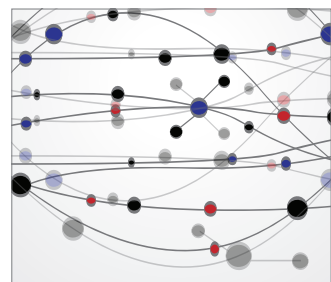

The Scientific World Journal
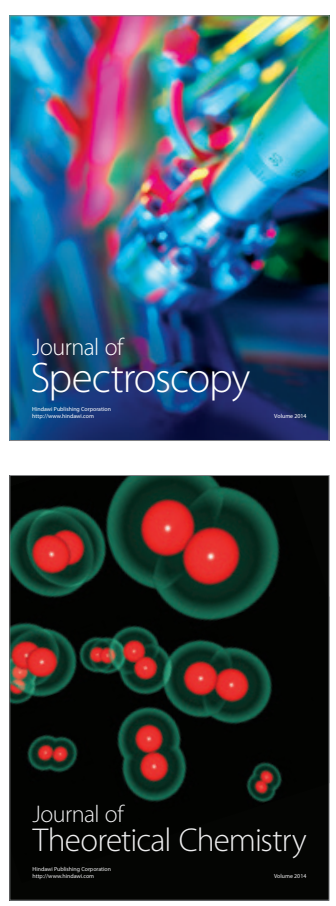
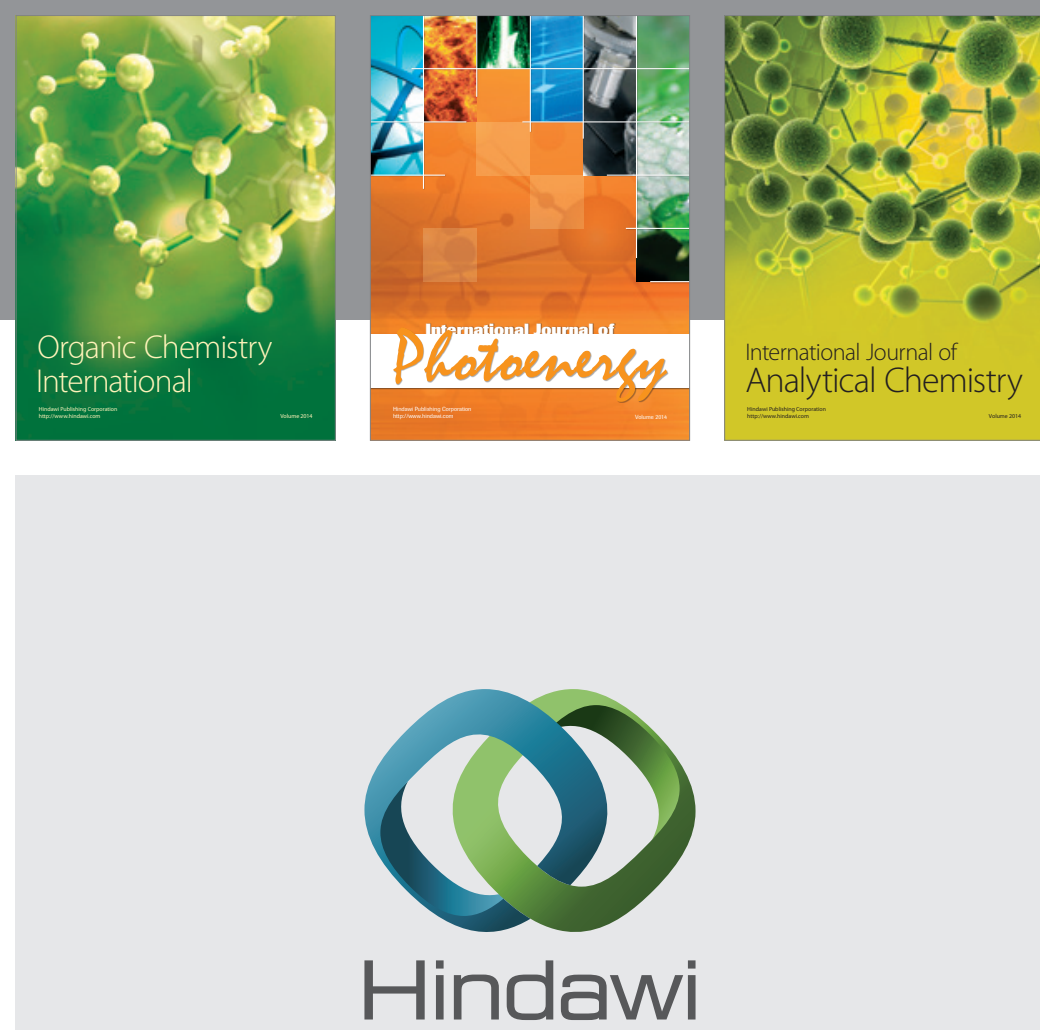

Submit your manuscripts at

http://www.hindawi.com
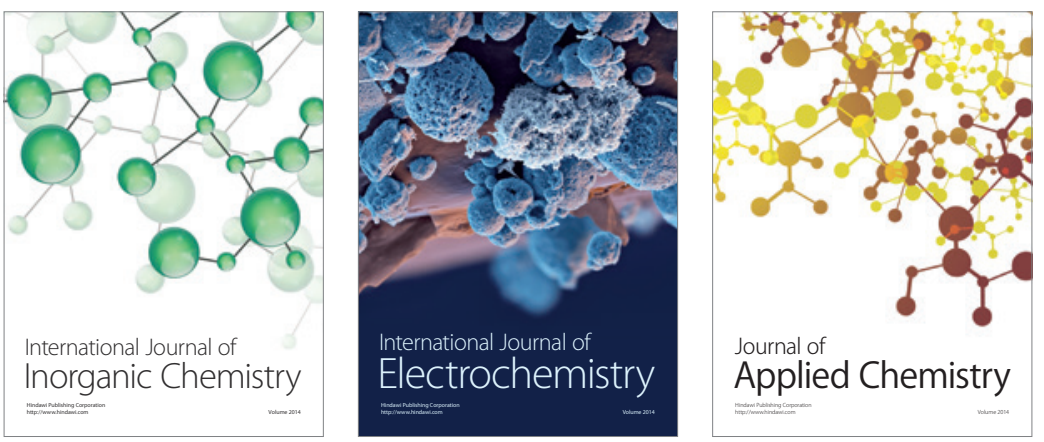

Journal of

Applied Chemistry
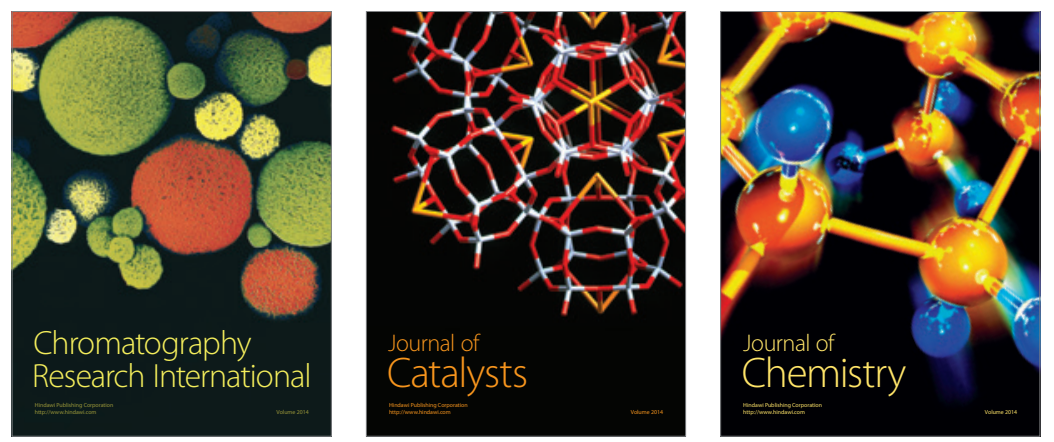
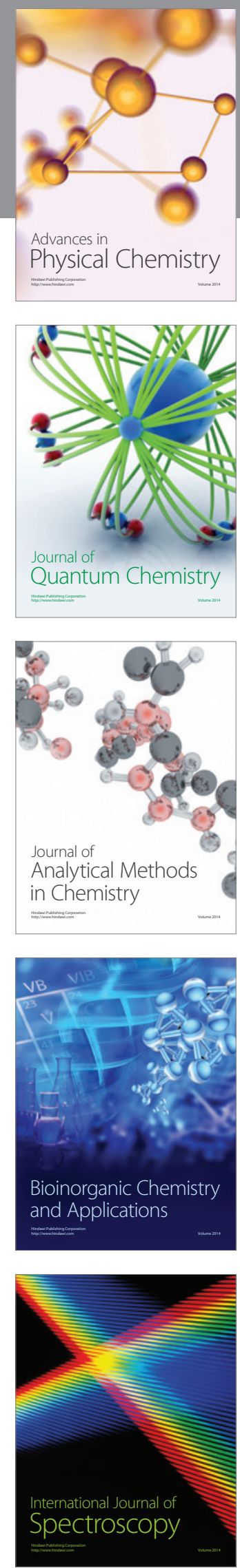